\section{Max Aebi}

Received: 26 October 2005

Accepted: 26 October 2005

Published online: 18 November 2005

(c) Springer-Verlag 2005

M. Aebi

Institute for Evaluative Research in Orthopaedic Surgery, University of Bern, Bern, Switzerland

M. Aebi

Department of Orthopaedics,

Hirslanden-Salem Hospital,

Stauffacherstrasse 78, 3014 Bern,

Switzerland

E-mail: max.aebi@MEMcenter.unibe.ch

Tel.: + 41-31-6315930

Fax: + 41-31-6315931

\title{
The adult scoliosis
}

Abstract Adult scoliosis is defined as a spinal deformity in a skeletally mature patient with a Cobb angle of more than $10^{\circ}$ in the coronal plain. Adult scoliosis can be separated into four major groups: Type 1: Primary degenerative scoliosis, mostly on the basis of a disc and/or facet joint arthritis, affecting those structures asymmetrically with predominantly back pain symptoms, often accompanied either by signs of spinal stenosis (central as well as lateral stenosis) or without. These curves are often classified as "de novo" scoliosis. Type 2: Idiopathic adolescent scoliosis of the thoracic and/or lumbar spine which progresses in adult life and is usually combined with secondary degeneration and/or imbalance. Some patients had either no surgical treatment or a surgical correction and fusion in adolescence in either the thoracic or thoracolumbar spine. Those patients may develop secondary degeneration and progression of the adjacent curve; in this case those curves belong to the type 3a.Type 3: Secondary adult curves: (a) In the context of an oblique pelvis, for instance, due to a leg length discrepancy or hip pathology or as a secondary curve in idiopathic, neuromuscular and congenital scoliosis, or asymmetrical anomalies at the lumbosacral junction; (b) In the context of a metabolic bone disease (mostly osteoporosis) combined with asym- metric arthritic disease and/or vertebral fractures. Sometimes it is difficult to decide, what exactly the primary cause of the curve was, once it has significantly progressed.

However, once an asymmetric load or degeneration occurs, the pathomorphology and pathomechanism in adult scoliosis predominantly located in the lumbar or thoracolumbar spine is quite predictable. Asymmetric degeneration leads to increased asymmetric load and therefore to a progression of the degeneration and deformity, as either scoliosis and/or kyphosis. The progression of a curve is further supported by osteoporosis, particularly in post-menopausal female patients. The destruction of facet joints, joint capsules, discs and ligaments may create mono- or multisegmental instability and finally spinal stenosis. These patients present themselves predominantly with back pain, then leg pain and claudication symptoms, rarely with neurological deficit, and almost never with questions related to cosmetics. The diagnostic evaluation includes static and dynamic imaging, myelo-CT, as well as invasive diagnostic procedures like discograms, facet blocks, epidural and root blocks and immobilization tests. These tests may correlate with the clinical and the pathomorphological findings and may also offer the least invasive and most rational treatment 
for the patient. The treatment is then tailored to the specific symptomatology of the patient. Surgical management consists of either decompression, correction, stabilization and fusion procedures or a combination of all of these. Surgical procedure is usually complex and has to deal with a whole array of specific problems like the age and the general medical condition of the patient, the length of the fusion, the condition of the adjacent segments, the condition of the lumbosacral junction, osteoporosis and possibly previous scoliosis surgery, and last but not least, usually with a long history of chronified back pain and muscle imbalance which may be very difficult to be influenced. Although this surgery is demanding, the morbidity cannot be considered significantly higher than in other established orthopaedic procedures, like hip replacement, in the same age group of patients. Overall, a satisfactory outcome can be expected in well-differentiated indications and properly tailored surgical procedures, although until today prospective, controlled studies with outcome measures and pre- and post-operative patient's health status are lacking. As patients, who present themselves with significant clinical problems in the context of adult scoliosis, get older, minimal invasive procedures to address exactly the most relevant clinical problem may become more and more important, basically ignoring the overall deformity and degeneration of the spine.

Keywords Adult scoliosis - Degenerative scoliosis - Spinal stenosis - Adult deformity - Secondary scoliosis

\section{Introduction}

Twenty-five years ago, a book chapter about scoliosis with special emphasis on the adult and/or degenerative scoliosis was relatively small $[5,11,20,43,53,62,64]$. Most of the pages were devoted to scoliosis in childhood and adolescence. Only the introduction of spinal instrumentation, first Harrington rods and Dwyer instrumentation, and later Zielke, and finally CD-instrumentation with all the following third generation pedicle instrumentations, shifted the focus to the major problem of the adult scoliosis [1, 2, 8, 13, 23, 27, 32, 35, 38, 40, 45, 58, 59, 62]. This disorder has been known for some time, but only a very few surgeons dealt with it. Patients were in an age group which was considered to be too risky to undergo major spine surgery; the surgical technical issues were widely unsolved due to the lack of powerful instrumentation; the bone stock was considered too poor for a major corrective surgery; and the patients were generally made to believe that they had to live with this ailment.

Progress in surgical techniques and technology is significantly supported by progress in anaesthesia for spinal surgery and by more sophisticated and precise diagnostic imaging and differentiated application of invasive and functional diagnostic tests. Increased patient awareness, the patient's unwillingness to accept their limitations and pains [54], and the gradual shift in the demographics towards a "grey society", make adult scoliosis with all of its different forms and clinical presentations, a much more frequent problem in a general spine practice than the scoliosis of children and adolescents. This trend is likely to continue when we consider the fact that in 25 years from now, a significant part (more than 10\%) of the population in the industrialized societies will be over 65 years old.

\section{Classification}

A scoliosis is diagnosed in adult patients when it occurs or becomes relevant after skeletal maturity with a Cobb angle of more than $10^{\circ}$ in the frontal plain $[1,55]$.

Type 1: Primary degenerative scoliosis ("de novo" form), mostly located in the thoracolumbar or lumbar spine [6, 19, 20 24, 25 27, 33, 43, 48, 52, 53].

Type 2: Progressive idiopathic scoliosis in adult life of the thoracic, thoracolumbar, and/or lumbar spine $[5,8$, $36,42,46,61,71,72]$.

Type 3: Secondary degenerative scoliosis.

(a) Scoliosis following idiopathic or other forms of scoliosis or occurring in the context of a pelvic obliquity due to a leg length discrepancy, hip pathology or a lumbosacral transitional anomaly, mostly located in the thoracolumbar, lumbar or lumbosacral spine $[11,24,34,44,50,64]$.

(b) Scoliosis secondary to metabolic bone disease (mostly osteoporosis) combined with asymmetric arthritic disease and/or vertebral fractures $[10,15$, $29,51,70]$.

Therefore, scoliosis can be present since childhood or adolescence and become progressive and/or symptomatic in adult life; or scoliosis may appear "de novo" in adult life without any precedence in earlier life.

Clinically, the most prominent groups are secondary (type 3) and primary (type 1) degenerative adult scoliosis. In elderly patients, both forms of scoliosis may be aggravated by osteoporosis, which also holds true for the type 2 scoliosis [24, 29, 70]. All three types of scoliosis may primarily appear at a certain stage as degenerative scoliosis, and degenerative scoliosis is 
therefore the main bulk of adult scoliosis. Beyond the proposed classification, the degenerative adult scoliosis could also be subdivided into scoliosis which have their aetiology in the spine itself and those scoliosis with the aetiology beyond the spine (Table 1). Schwab et al. proposed recently a radiographic classification including type I-III scoliosis, characterized by the $\mathrm{a} / \mathrm{p}$ and lateral view in standing position. They correlated the classification I-III with increasing severity of self-reported pain and disability [55]. Boachie-Adjei [8] considers specifically the idiopathic adult scoliosis (our type 2 scoliosis) and uses the age as a classifying criteria combined with degenerated changes: patients with idiopathic adult scoliosis below and above 40 years of age.

This review will concentrate on the forms of adult scoliosis which present themselves most frequently in a spinal practice and which are considered in the abovepresented classification.

Type 1 scoliosis: the primary degenerative scoliosis ("de novo" scoliosis) (Fig. 1)

The primary degenerative curve develops mostly on the grounds of primarily limited disc degeneration in one or more motion segments. This curve also could be termed "discogenic curve" and is basically the result of an asymmetric degenerative change of the disc with the consecutive development of a frontal deviation and concomitant rotation with the facet joints on one side as a pivot (Fig. 1). The apex of this curve is usually between L3 and L4 or L2 and L3 or, second most frequent, between L1 and L2. These curves tend to go along with a significant rotational translation of the apical vertebra. In some cases the primary cause of the degenerative process may be localized in the facet joints where a wide variety of dystrophic formation, malformation, and misalignment can occur. When this occurs at the lumbosacral junction, then the curve belongs rather to the type 3 a curves, following lumbosacral anomalies.

It is difficult to state whether some curves in this group could be considered as "resting" idiopathic scoliosis. There are obviously curves that only develop in adult life and may appear like idiopathic scoliotic curves; however, upon closer look, they rather may have developed on the basis of a degenerated disc. The primarily degenerative curves usually are less severe in terms of frontal angulation than the curves in secondary degenerative idiopathic scoliosis [24, 25]. The primary degenerative scoliosis is therefore mostly a lumbar or thoracolumbar curve consisting of a frontal as well as a sagittal deviation in the

Table 1 Potential of curve progression

\begin{tabular}{|c|c|c|c|}
\hline Type & Description & Etiology & $\begin{array}{l}\text { Problem located } \\
\text { in the spine } \\
\text { beyond the spine }\end{array}$ \\
\hline Type I & $\begin{array}{l}\text { Primary degenerative scoliosis } \\
\text { ("de novo" scoliosis) } \\
\text { mostly lumbar } \\
\text { or thoracolumbar curve } \\
\text { apex at } \mathrm{L} 2 / 3 \text { or } \mathrm{L} / 4 \text { most } \\
\text { frequently }\end{array}$ & $\begin{array}{l}\text { Asymmetric disc } \\
\text { degeneration and facet } \\
\text { joint degeneration }\end{array}$ & + \\
\hline Type II & $\begin{array}{l}\text { Progressive idiopathic } \\
\text { scoliosis of the } \\
\text { lumbar and/or } \\
\text { thoracolumbar spine } \\
\text { (e.g. double major curve) }\end{array}$ & $\begin{array}{l}\text { Idiopathic scoliosis present } \\
\text { since adolescence or } \\
\text { childhood, progression } \\
\text { due to mechanical } \\
\text { reasons or bony and/or } \\
\text { degenerative changes }\end{array}$ & + \\
\hline Type III (a) & $\begin{array}{l}\text { Secondary adult scoliosis } \\
\text { mostly thoracolumbar, } \\
\text { lumbar-umbosacral }\end{array}$ & $\begin{array}{l}\text { Secondary to an adjacent } \\
\text { thoracic or thoracolumbar } \\
\text { curve of idiopathic, } \\
\text { neuromuscular or } \\
\text { congenital origin } \\
\text { Obliquity of the pelvis due } \\
\text { to leg length discrepancy } \\
\text { or hip pathology with } \\
\text { secondary lumbar/ } \\
\text { thoracolumbar curve } \\
\text { Lumbosacral transitional anomaly }\end{array}$ & + \\
\hline Type III (b) & $\begin{array}{l}\text { Deformity progressing } \\
\text { mostly due to bone } \\
\text { weakness with, e.g., } \\
\text { osteoporotic fracture with } \\
\text { secondary deformity }\end{array}$ & Metabolic bone disease, osteoporosis & + \\
\hline
\end{tabular}


Fig. 1 Type 1 adult scoliosis: de novo scoliosis. a at 33 years $\left(8^{\circ}\right), \mathbf{b}$ at 50 years $\left(25^{\circ}\right)$, c at 55 years $\left(40^{\circ}\right)$
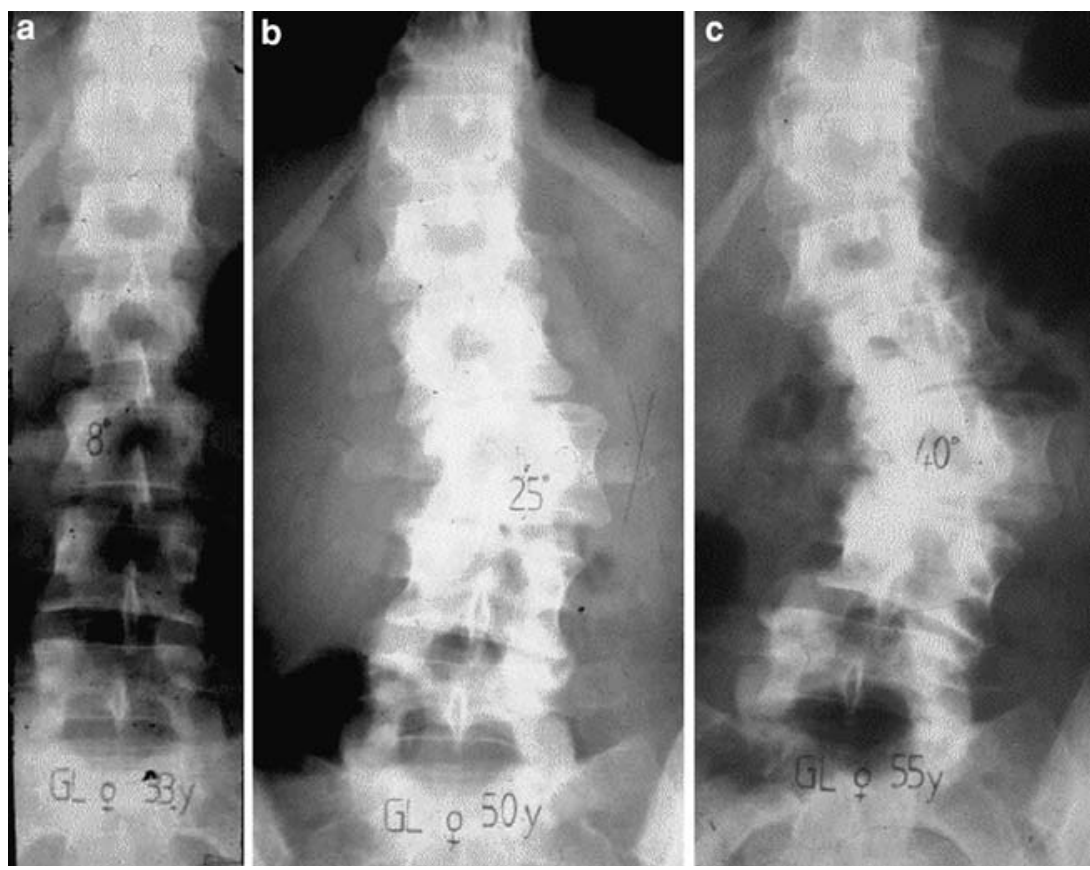

form of mostly a flat back or lumbar kyphosis $[5,6,8,19$, $23,31,36]$. The sagittal malalignment is usually responsible for the severe postural back pain of the patients. These curves are shorter than the idiopathic curves an$\mathrm{d}$ - at least in the beginning - the deformity of the individual vertebral body is less expressed than in idiopathic scoliosis $[24,25]$. This only occurs as a consequence of erosion and destruction of the endplates and facet joints due to spondylosis and spondylarthritis. Also, there is a difference in the bone density between the primary and secondary degenerative curves. Spinal stenosis is more often seen in primary degenerative scoliosis than in secondary degenerated idiopathic curves [2, 6, 8, 21, 26, 44]. The disc degeneration ends up with spondylosis, disc bulging, osteophytes, and facet joint arthritis with hypertrophic capsules, ligamentum flavum, and calcification of these structures with osteophytes, all on the costs of the space in the spinal canal and foramina, thus contributing to the formation of spinal stenosis, be it a foraminal lateral stenosis or a central stenosis or both (Fig. 2).

Type 2 scoliosis: progressive idiopathic scoliosis in adult life (Fig. 3)

The idiopathic curves and curves with other aetiology of secondary degeneration present themselves in a variety of forms, depending on whether these curves have been treated non-surgically or not at all or whether they have had a fusion, with or without instrumentation, of the main thoracic and thoracolumbar curve [46]. In the latter case the degeneration appears in the adjacent curve and belongs to the type 3a curves (see below) (Figs. 3, 4). In both situations, however, there may be a significant degeneration and deformity present in the sagittal as well as in the frontal plain of the short lumbar curve. The sagittal deformity is almost always exclusively a flat back syndrome or a loss of physiological lordosis and in extreme situations a real kyphosis. The degenerated idiopathic scoliosis mostly in the lumbar and/or thoracolumbar spine is quite frequently combined with spinal stenosis at a relatively young age, specifically in the adjacent lower segment after Harrington instrumentation. This adjacent segmental spinal stenosis, mostly below a long fused idiopathic scoliosis, appears about 15-20 years post-surgical with Harrington rods (Fig. 5). There are not yet similar long-term results available for cases which have been treated with one of the CD-type third generation instrumentation that allow superior restoration of the sagittal alignment, possibly protecting the spine from developing rapid adjacent segment degeneration $[3,4,7,21,39,56]$.

Type 3 scoliosis:

\section{Secondary degenerative scoliosis (Fig. 6)}

Adult secondary degenerative scoliosis is mostly located in the thoracolumbar and lumbar as well as lumbosacral spine. This scoliosis occurs either with its cause within the spine or outside the spine. Those scoliosis with the cause inside of the spine are either secondary to an adjacent curve, be it an idiopathic, neuromuscular or congenital curve, or it may be the consequence of a 

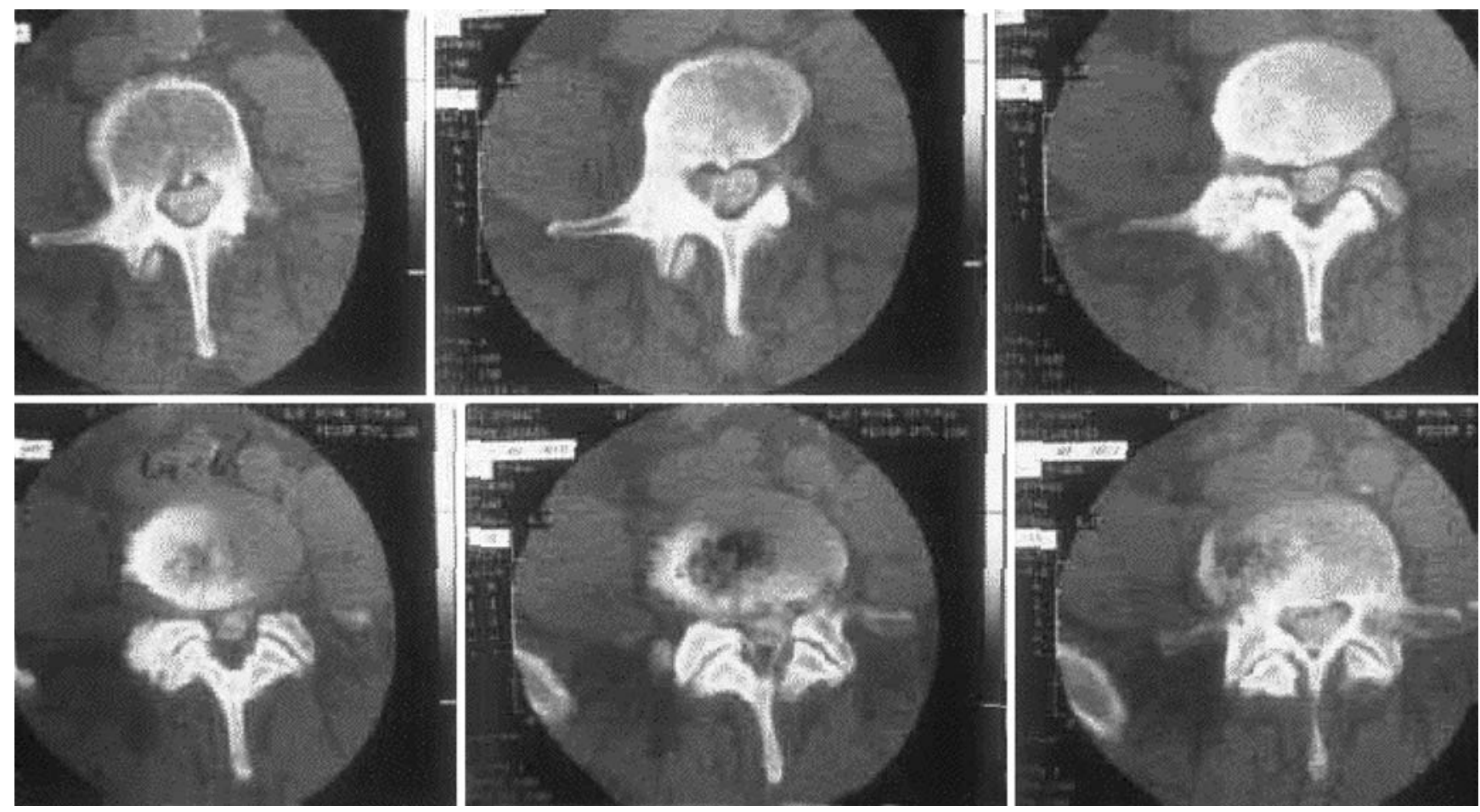

Fig. 2 Secondary changes in degenerative scoliosis: facet joint hypertrophy, recessal stenosis

lumbosacral anomaly, specifically with a hemisacralization (Fig. 6). Scoliosis outside of the spine is due to pelvic obliquity in the context of a hip pathology or a leg length discrepancy (Fig. 7). These secondary curves with the causes outside of the spine primarily do not have a relevant rotation, however are basically deviations in the frontal plain. Only over time there is a translational displacement of vertebras close to the apex.

\section{Adult scoliosis due to bone weakness (Fig. 8)}

These deformities are mostly due to metabolic bone disease or diseases which have a secondary impact on the strength of the bone (e.g. Morbus Adison) (Fig. 8). The most frequent cause for a secondary deformity due to metabolic bone disease is osteoporosis. Owing to bone weakness, there may be fractures, which create an asymmetric configuration with expression of either kyphosis or scoliosis or both together. It may also occur when a preexisting scoliosis, respectively kyphosis, is aggravated by an osteoporotic fracture $[29,65,70]$.

\section{Pathomorphology and pathomechanism in adult scoliosis}

Degenerative adult scoliosis, specifically in the lumbar spine, is characterized by quite a uniform pathomor- phology and pathomechanism. The asymmetric degeneration of the disc and/or the facet joints leads to an asymmetric loading of the spinal segment and consequently of a whole spinal area. This again leads to an asymmetric deformity, for example, scoliosis and/or kyphosis. Such a deformity again triggers asymmetric degeneration and induces asymmetric loading, creating a vicious circle (Fig. 9) and enhancing curve progression. On the one hand, the curve progression is given by the pathomechanism of an adult degenerative curve, and on the other hand by the specific bone metabolism of the post-menopause female patients with a certain degree of osteoporosis, who are most frequently affected by the degenerative form of scoliosis. The potential of individual asymmetric deformation and collapse in the weak osteoporotic vertebra is clearly increased and contributes further to the curve progression.

The destruction of discs, facet joints and joint capsules usually ends in some form of uni- or multisegmental sagittal and/or frontal latent or obvious instability. There may be not only a spondylolisthesis, meaning a slip in the sagittal plain, but also translational dislocations in the frontal plain or rather threedimensionally when expressing itself in a rotational dislocation (Figs. 1, 3, 6, 15). The biological reaction to an unstable joint or, in the case of the spine, an unstable segment, is the formation of osteophytes at the facet joints (spondylarthritis) and at the vertebral endplates (spondylosis), both contributing to the increasing narrowing of the spinal canal together with 

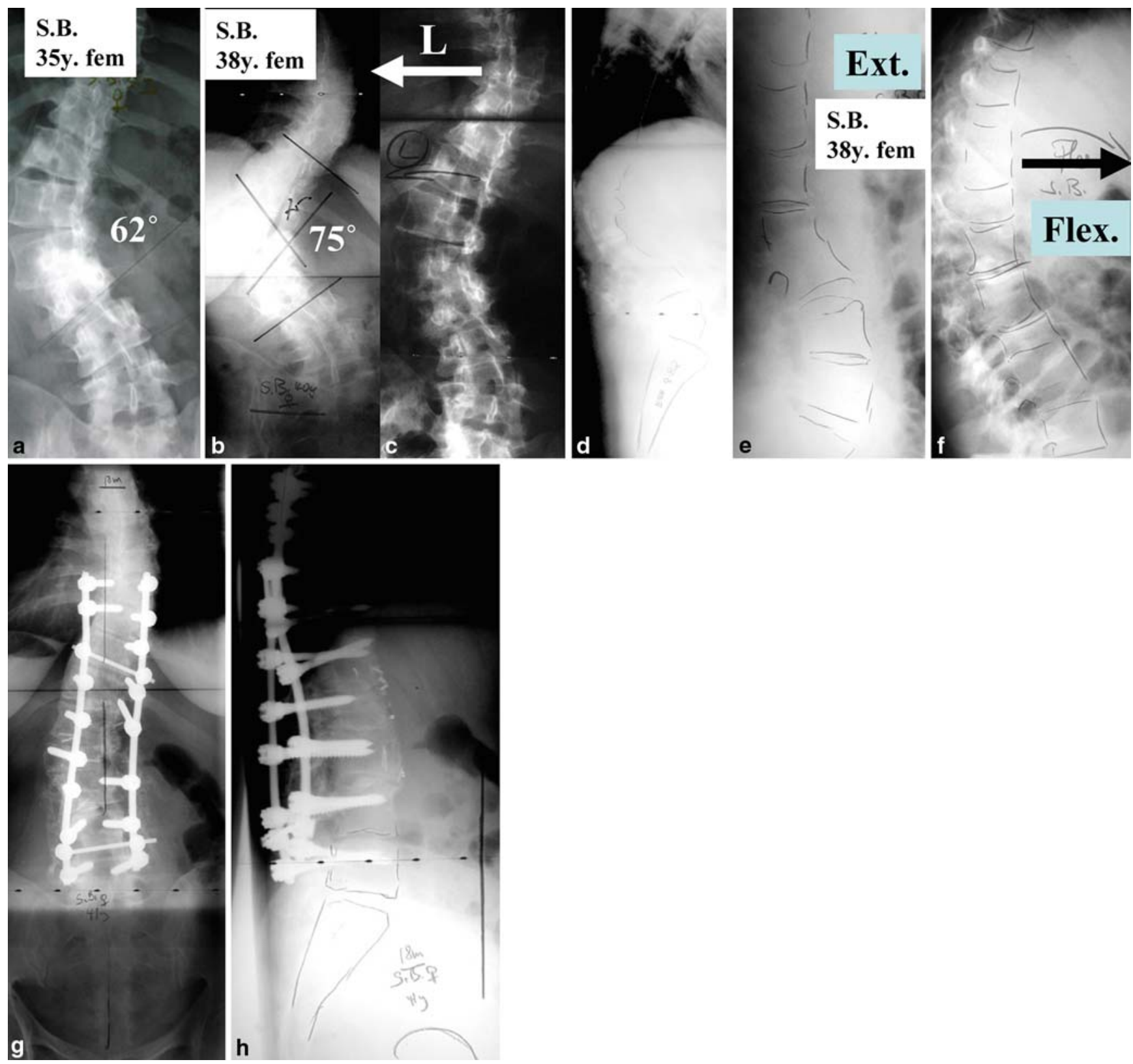

Fig. 3 Young female teacher with progressive idiopathic scoliosis. a At 35 years, $62^{\circ}$, b at 38 years progressed to $75^{\circ}$, c left bending with some correction, d significant lumbar kyphosis, e partial correction by extension, $\mathbf{f}$ flexion of thoracic spine, $\mathbf{g}$ and h 18 months postoperatively after (1) anterior LISS release and fusion with beta-TCP (Chronos $\left.{ }^{\circledR}\right)$ autologous bone mixture and (2) posterior correction and stabilization and fusion with USS during the same anaesthesia. Restoration of the lordosis

the hypertrophy and calcification of the ligamentum flavum and joint capsules, creating central and recessal spinal stenosis [66] (see also Fig. 2). These pathomorphological and pathomechanical relationships and their significance for the clinical presentation of an

adult degenerative scoliosis are expressed schematically in Fig. 10. The osteophytes of the facet joints and the spondylotic osteophytes, however, may not sufficiently stabilize a diseased spinal segment; such a condition leads to a dynamic, mostly foraminal stenosis with radicular pain or claudication type pain (e.g. Fig. 11).

\section{Clinical presentation}

Pain

The most frequent clinical problem of adult scoliosis is back pain $[3,6,19,31,56,73]$ and presents itself with 

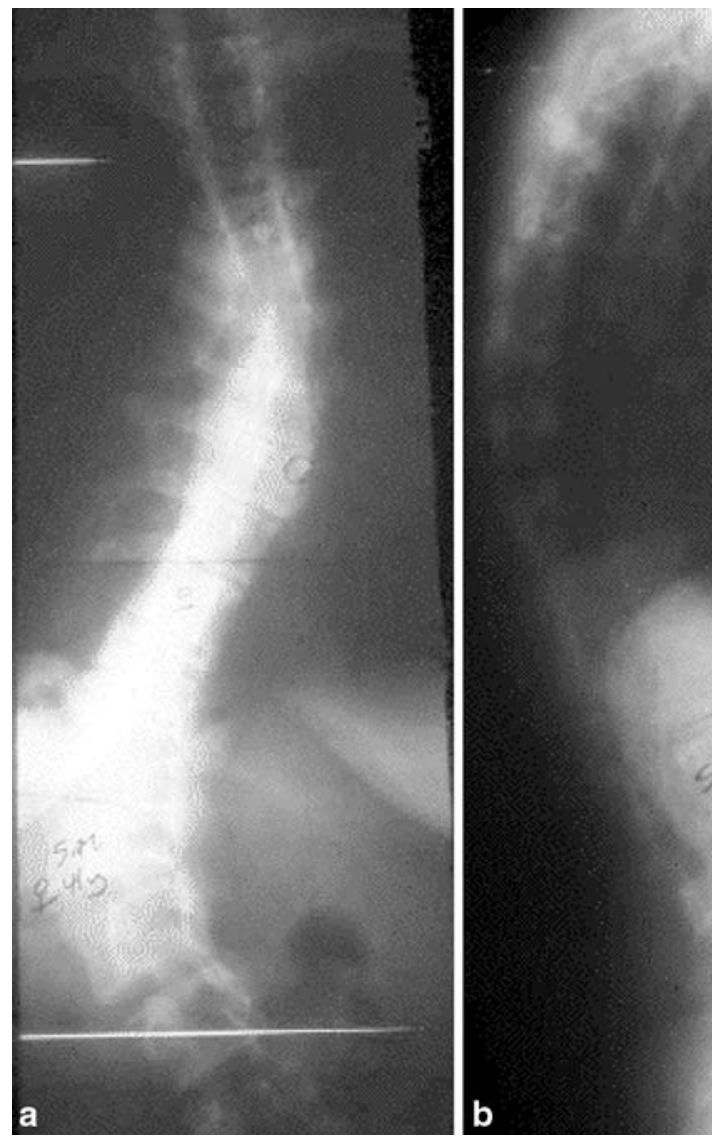

Fig. 4 a and b Double major idiopathic scoliosis in a 41-year-old female patient with increasing back pain in the last few years and subjective progression of the curve. c Long fusion to the sacrum with development of a non-union and loss of balance after a year postoperatively. d Osteotomy at L2/3, cut of the rod and correction of the malposition by reconnecting the right cut rod and PLIF at the lumbosacral junction. Now with good balance and almost no pain

a multiform mosaic of symptoms. Back pain at the site of the curve can be localized either at the apex or in its concavity, and facet joint pain can be localized in the countercurve from below the curve to above the curve. The back pain can be combined with radicular leg pain. It can be the expression of a muscular fatigue or of a real mechanical instability. Unbalanced, overloaded, and stressed, paravertebral back muscles may become very sore and in return will not contribute to balance the muscle play, consequently becoming part of a vicious circle. This is especially true when the lumbar curve is accompanied by the loss of lumbar lordosis [22]. This muscular pain is rather diffuse, distributed over the lower back, and often permanent at the insertion of the muscle tendons at the iliac crest, sacrum, os coccys, and bony processes of the spine.

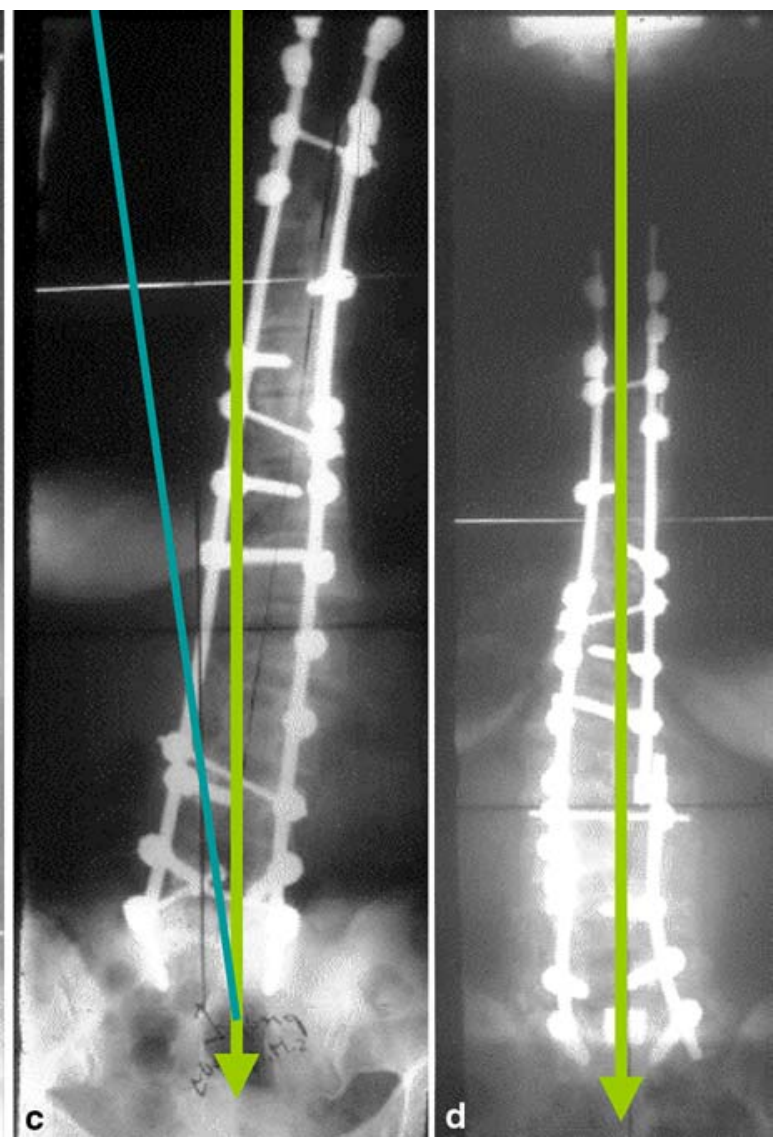

The back pain can be constant and non-specific, which is a bad prognostic sign regarding the treatment outcome. The pain, however, can be present only when the patient is upright, especially when standing and sitting, presenting as a so-called axial back pain, or only during certain movements or physical activities, pointing rather to a mechanically unstable segment or a whole spinal region. The patients often indicate that they can control their pain well, when lying down flat or on their side and when the axial load is taken off the spine.

\section{Claudication}

The second important symptom of adult degenerative scoliosis is radicular pain and claudication symptoms when standing or walking [57, 73]. The patient can have true radicular pain due to a localized compression or root traction (root compromise is not necessarily on the concave side where we may suppose narrowed foramens, but often on the convex side, rather expressing a dynamic overstretch of a root). There may, however, be a single- or multilevel spinal stenosis which can be central or more recessal, creating claudication symptoms $[19,24,27,53,56]$. Root com- 


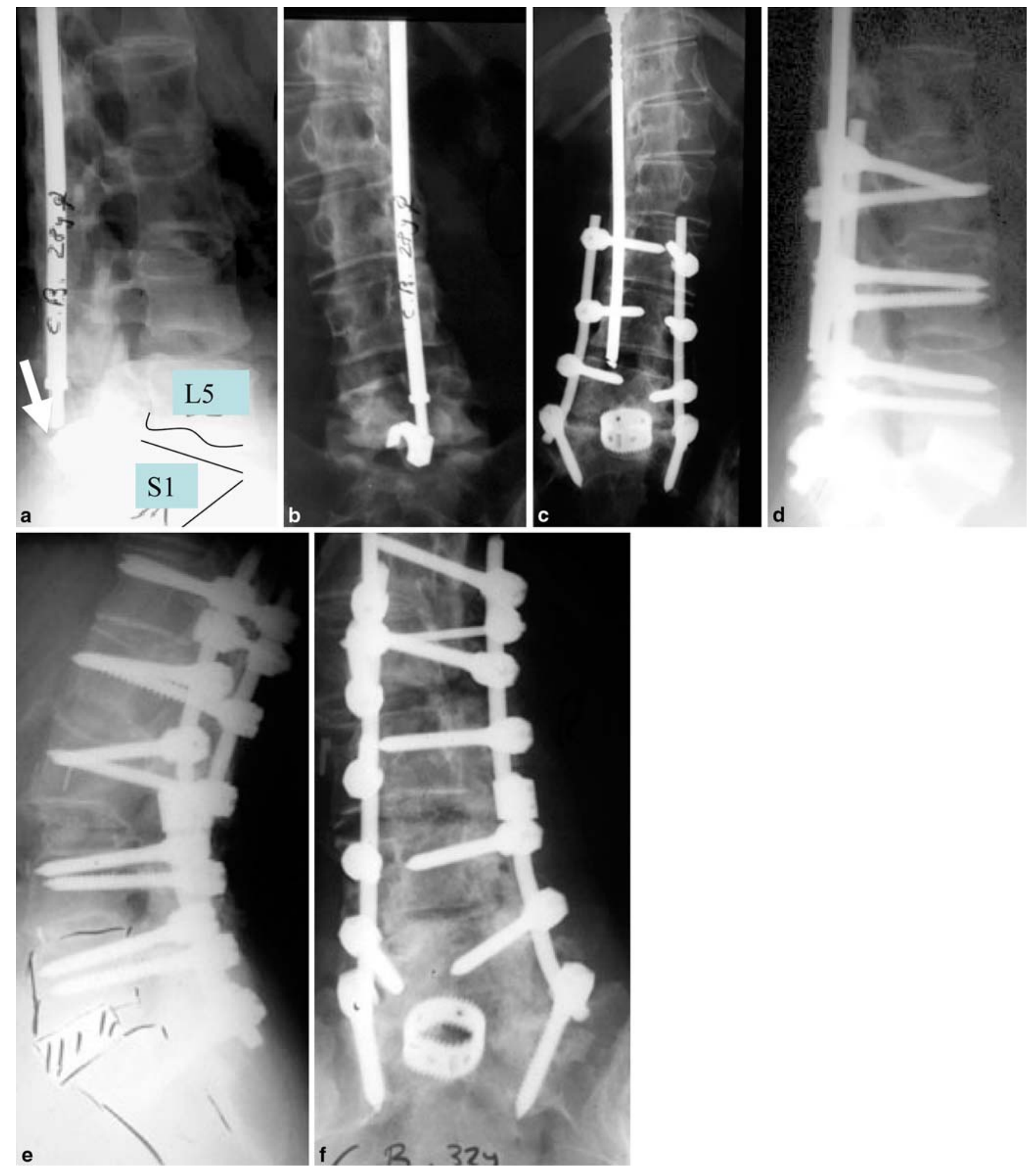


Fig. 5 a and b A 28-year-old female patient 15 years after Harrington correction and fusion to L5. Flat back, spinal stenosis at L5/S1 and disconnection of the rod off the hook seating on the arch of L5 (arrow). c and d Decompression and attempt to correct in L4/5 and L5/S1, refusion with pedicle screws and anterior cage at L5/S1. Remaining flat back and consecutive back pain. $\mathbf{e}$ and $\mathbf{f}$ Three years after rebalancing the spine by posterior wedge osteotomy at L3/4 and restabilization and fusion 4 years after second surgery. Back pain almost entirely disappeared

pressions can occur at the bottom of the curve or at the transition to the sacrum and can be linked to a hypermobility of an overloaded bottom segment, especially in cases of stiff curves. Short lumbosacral or lumbar curves as countercurves to long fused thoracolumbar scoliosis often show a severe spinal stenosis at the transition from the stiff upper spinal area to the lower lumbosacral area (Fig. 11).

\section{Neurological deficit}

The third important clinical presentation may manifest itself as a real neurological deficit, including individual roots, several roots, or the whole cauda equina with apparent bladder and rectal sphincter problems. An objective neurological deficit, however, is rare and, when present, is due to a significantly compromised space in the spinal canal with a relatively acute aggravation and decompensation (Fig. 12). A sequester of a severely degenerated and dried out disc within the curve may be the cause of such an acute neurological deficit (Fig. 13). It can be accentuated or only become clinically relevant due to a latent or obvious segmental instability.

\section{Curve progression}

The fourth relevant symptom or sign is curve progression. Curve progression may be an issue from the moment the curve occurs in younger age. It may, however, only become relevant, when the curve has reached a certain amount of degrees and/or when osteoporotic asymmetric collapse may contribute relevantly to the curve. Once a curve has reached a certain extent of curve degrees, the progression will automatically follow due to the axial mechanical overload of individual facet joints and/or osteoporotic vertebral bodies. The progression of the curve may well be an indication for a surgical treatment. The surgeons have to be aware of the amount of aggravation which may occur, when nothing surgically is done. Patients do get older with all the medical consequences, which raise automatically the risk for a surgical intervention. Therefore, a surgical intervention may occasionally be indicated in order to avoid a further progression and degeneration in a patient with potential medical risks [3, 4. 7].

\section{Cosmesis}

In contrast to the adolescent idiopathic scoliosis, cosmesis almost never plays a role; patients see the orthopaedic surgeon because of a simple or more complex pain syndrome and/or neurological deficit. Cosmesis may occasionally play a role in younger patients below 40 years with an early secondary degenerated idiopathic thoracolumbar or lumbar scoliosis.

\section{Diagnostic evaluations}

In addition to the standard clinical examination, patients with symptomatic adult scoliosis need precise conventional imaging and often require interventional radiological procedures, such as sequential discograms, facet blocks, epidural blocks and preferentially, a myelogram combined with a CT scan [24, 25, 34, 36, 57]. A spiral CT is very useful in rapid reconstruction of the spine vertically and, in conjunction with the myelogram, obtaining a clear understanding of the pathology. MR imaging of degenerative scoliosis is often very polymorphic due to the complex pathology, parts of which may still be difficult to understand and may leave us uncertain as to the leading pathology. For example, deformity may be interpreted on one of the MR-cuts as spinal stenosis, since the whole deformity is not in the same plain.

In the context of the evaluation of the pain source, discograms and facet blocks are especially helpful since their findings may change the therapeutic approach. It is important, e.g., in lumbar curves, to find out whether the pain occurs within the curve, below the main curve (usually involving L4/5 and/or L5/S1), or rarely, above the curve at the thoracolumbar junction. Since the pain can be generated in one or several segments, it is recommended to perform the discograms sequentially in order to isolate the really painful segment. In addition, the discogram can be used as a provocative pain test, as well as a form of local anaesthesia in the disc, usually combined with some cortisone injection. Therefore, the discogram serves to provide both direct pain provocation and localization and as a double test for pain evaluation, when the pain disappears after the intradiscal depot of medication. Facet blocks should also be performed sequentially to catch the most probable pain generator level.

If, despite all these tests, the pain remains unexplained, it may be helpful in rare cases to put on a 
Arrows:

1: transitional anomaly

2: spondylolysis L5

* Plomb line from the center of the head
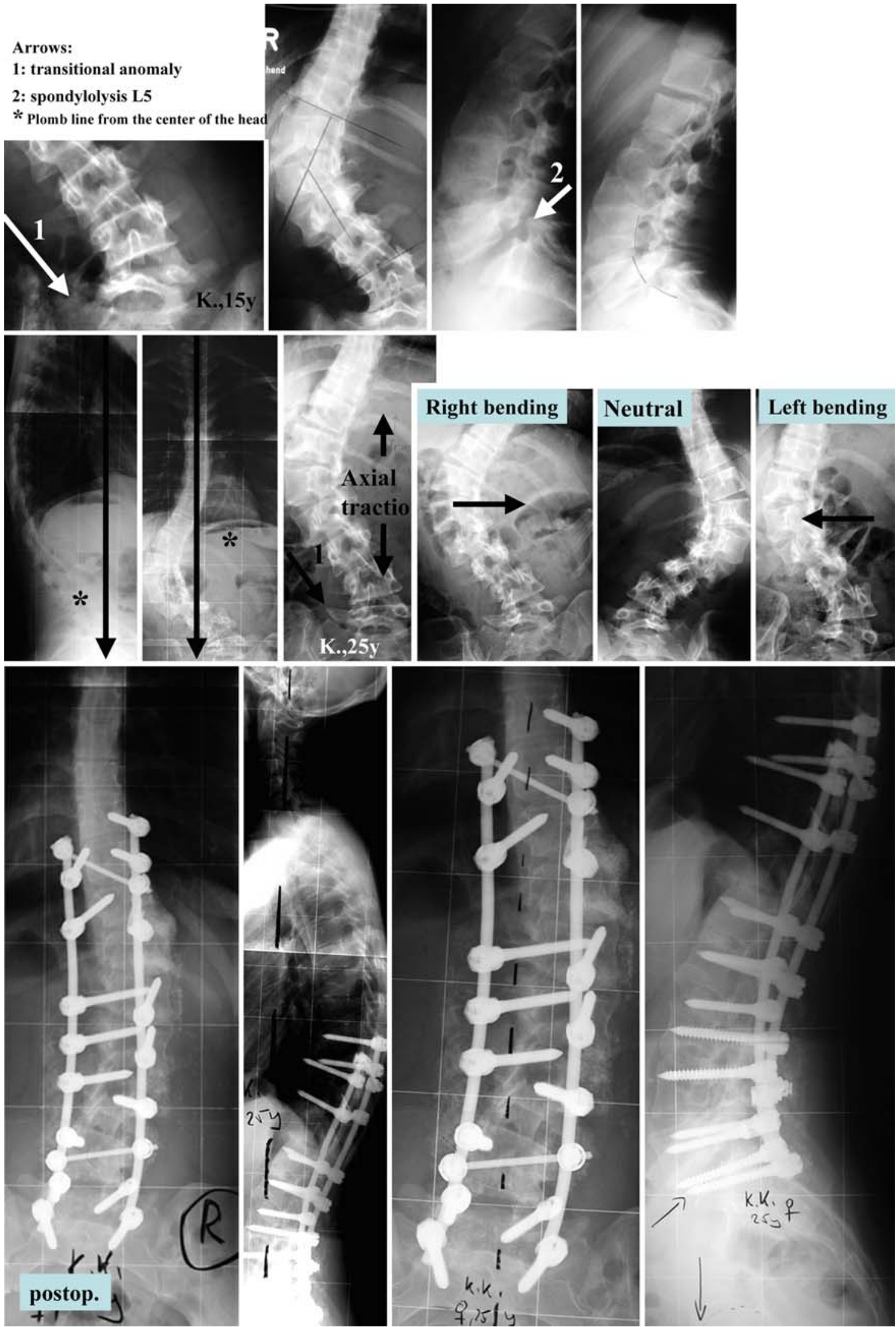
Fig. 6 Type 3a scoliosis in a 25-year-old female patient. Arrows (1) transitional anomaly; (2) spondylolysis L5. *Plomb line from the centre of the head

temporary cast in the form of a thoracolumbar orthosis (TLO) or thoracolumbosacral orthosis (TLSO) to see whether an overall stabilization and fusion of the whole scoliotic spinal area could be beneficial for the patient, specifically in cases of an overall tendency of the spine to statically collapse.

In elderly people with degenerative scoliosis displaying predominant symptoms of claudication, leg pain, and multilevel stenotic segments in the imaging, motor evoked potentials (MEP) may be helpful to identify the level responsible for the clinical presentation. A clear topographic diagnosis would certainly help to minimize the surgery in these patients.

The selective use of epidural blocks at stenotic levels or selective nerve root blocks is another helpful tool to identify the level clinically relevant to the symptomatology on the one side and as a therapeutic tool on the other side, in case surgery is not feasible or is decided to be delayed [67].

Fig. 7 Secondary degenerative scoliosis due to a hip arthrodesis for a posttraumatic damage of the left hip: left convex, long thoracolumbar curve with secondary rotational deformity

\section{Therapeutic decision (Fig. 14)}

The indication for or against surgery and, more specifically, the type of surgery to be performed, involves complex decision-making. Certainly, surgery is only an option when the non-surgical measures have no effect or do not promise any relevant long-term help.

The non-surgical treatment options $[9,20,34,46,67]$ consist basically of non-steroid anti-inflammatory medication, muscle relaxants, pain medication, muscle exercises, swimming and occasionally gentle traction, while avoiding manipulations and physical activation that may increase the pain. Therapeutic epidural and selective nerve root blocks as well as facet joint blocks may help to control the pain temporarily. Sometimes a well-fitted brace to support the painful spine area may be necessary.

In order to plan the most promising surgical procedure for each patient, a clear understanding of the prominent symptoms or clinical signs is mandatory. The symptoms and clinical signs, which can be addressed surgically, either individually or in concert are represented in Table 2 (see also Fig. 10).

The specific surgical answer to each of these signs or symptoms may vary depending on whether they occur individually or in the context of another. The surgical decision is also influenced by the patient's general health, age, condition of bone quality, and the patient's expectations [3, 15].
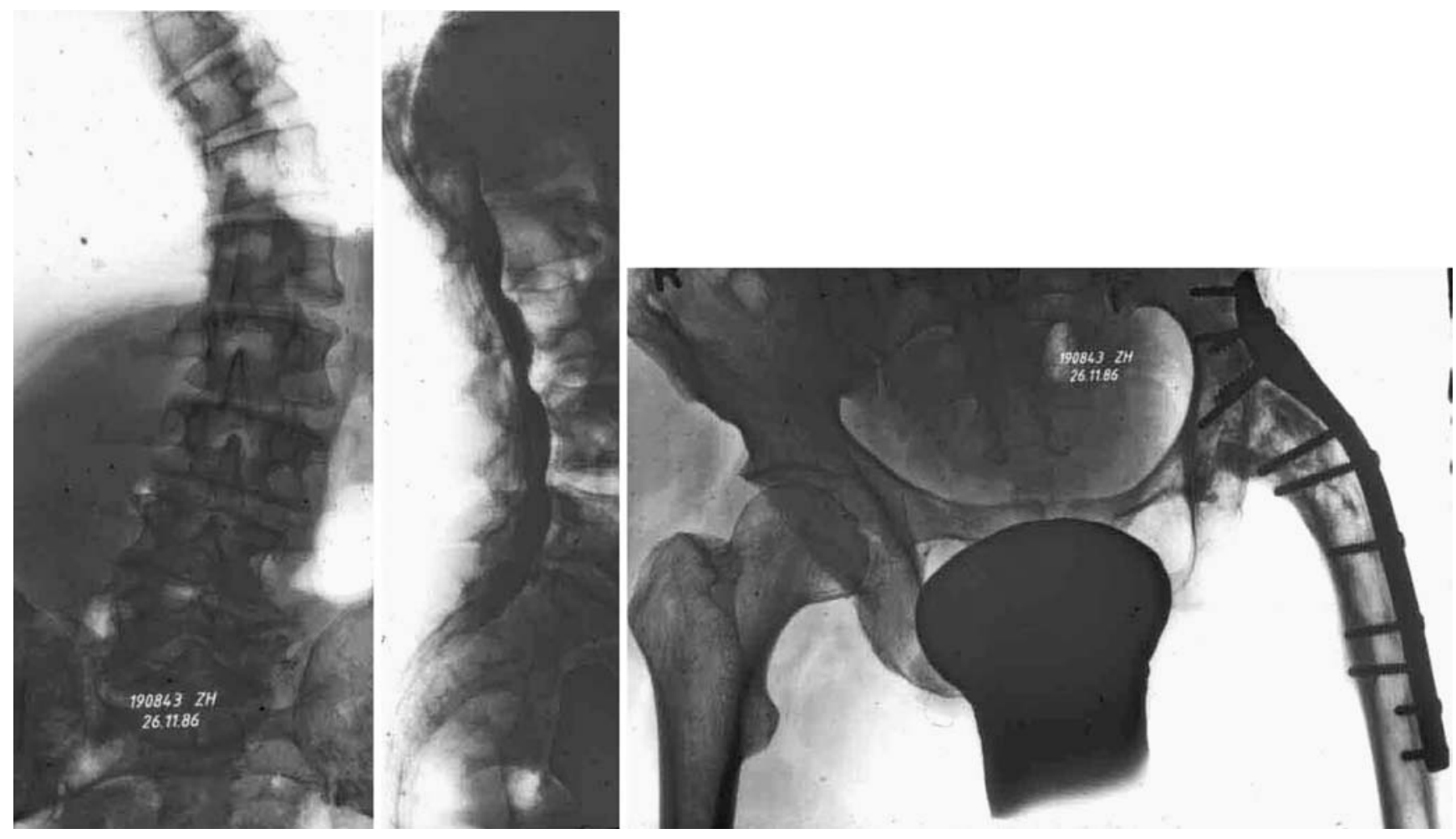

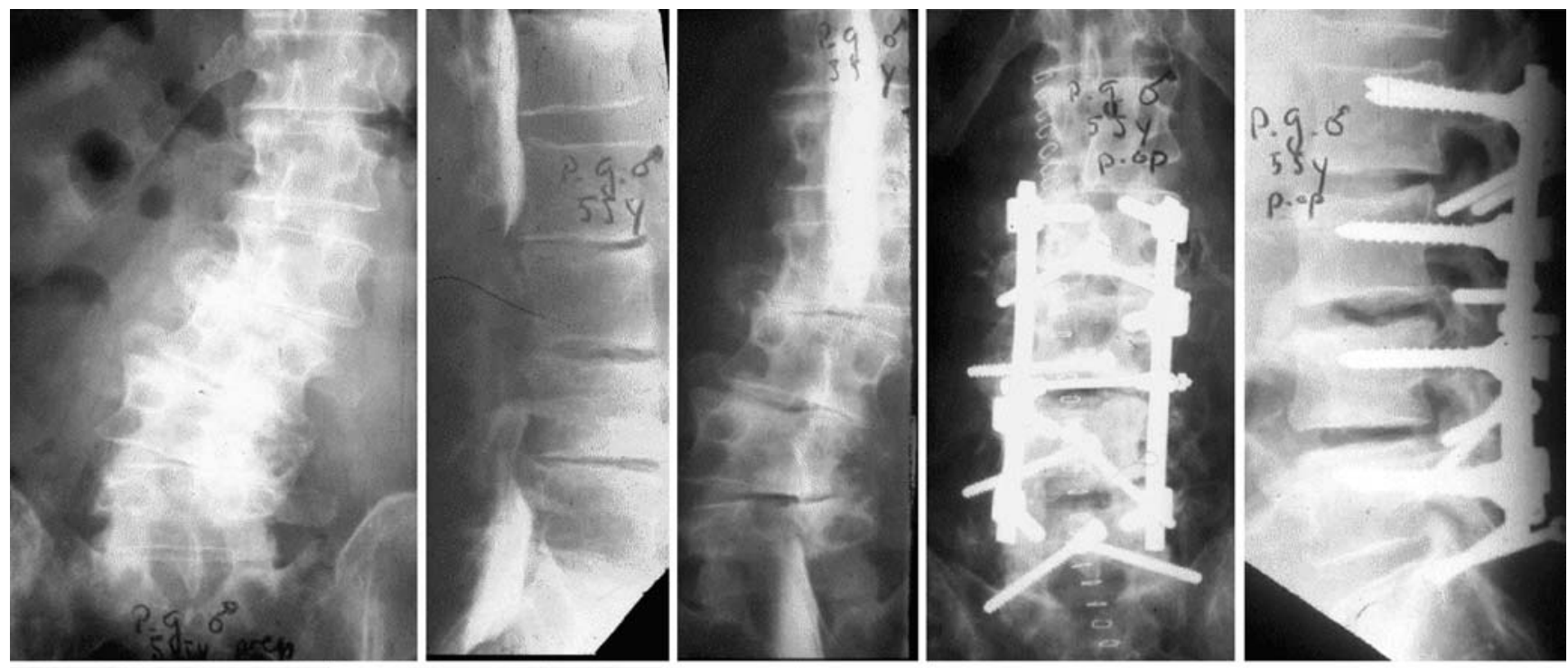
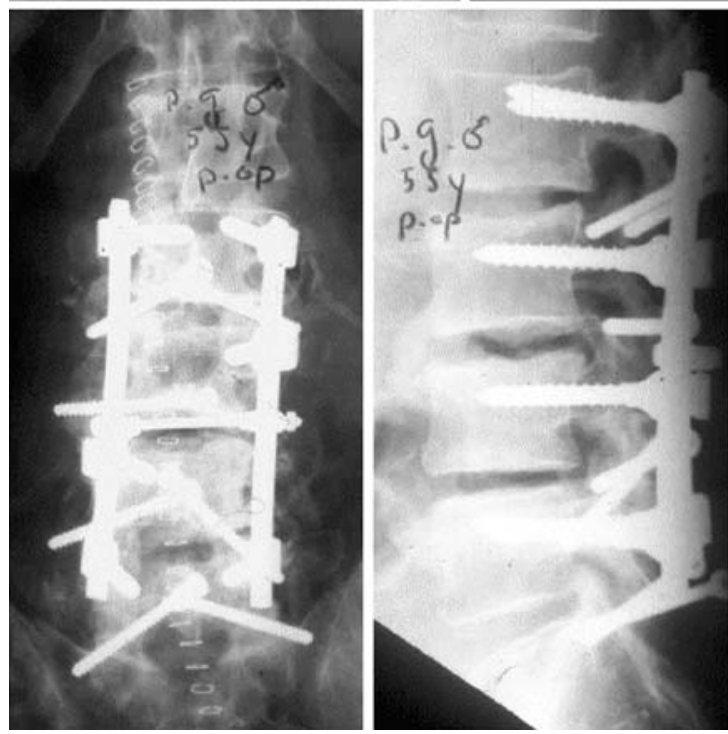

Fig. 8 Adult scoliosis in a 55-year-old male patient with $\mathrm{M}$. Addison: osteoporose, flat back and spinal stenosis. Decompression, stabilization and correction in the frontal plane, distraction, but not reestablishing lordosis. However, 2 years postoperatively, patient had no relevant back pain

The surgical concept involves three basic procedures which can be performed separately or together, depending on the patient's overall symptomatology.

\section{Surgical procedures}

A surgical approach to degenerative adult scoliosis is obviously complex in terms of decision making, i.e., ascertaining the surgical indication and choosing the patient and the procedure appropriately. The technical difficulties, however, are equally elaborated. The aggravating factors and difficulties for this type of surgery are manifold. Curve magnitude and age of the patients are, e.g., significant predictors of curve flexibility. The understanding of this association allows to better address treatment options over time [14].

The possible surgical technique can be divided in posterior, anterior or combined procedures. In all these procedures a simple decompression or stabilization can be done, or both can be combined $[2,9,16,32,38,41$, $56,68,69]$. In some cases, additional correction may be considered, either by clearly defined osteotomies or by sequential segmental correction through instrumentation. This is particularly of interest in combined sagittalfrontal rigid deformities.

\section{Decompression procedures}

Decompression may be done as a stand-alone procedure in cases of central or lateral stenosis and symptomatol- 


\section{Adult degenerative Scoliosis}

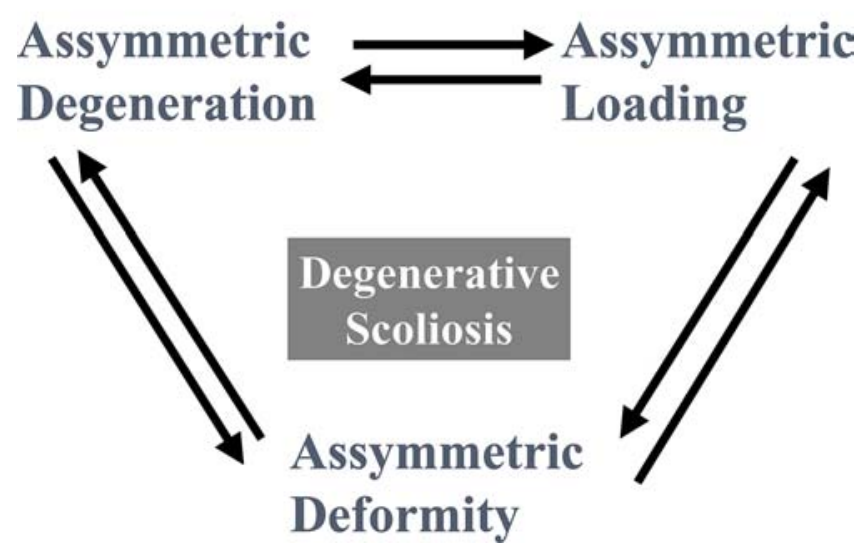

Fig. 9 Pathomechanism of adult degenerative scoliosis as a "vicious circle"

ogy limited to the legs, without relevant back pain, or together with instrumentation and fusion in cases of additional obvious instability, segmental dysfunction, or progressive deformity. Stand-alone decompression procedures in deformities are rarely indicated, although it may be attractive, particularly in elderly frail people. The decision exactly when a decompression alone is possible, is difficult to make, since a definite judgement about the degree of stability or instability is sometimes not possible on objective, scientific grounds alone. In clinical practice one learns regularly that the judgement was wrong and the chosen procedure not sufficient. It is easier sometimes to add a limited fusion and stabilization in the same session than to go back to do a second surgery in these often medically unstable patients (Fig. 11). The outcome is frequently complicated by either further collapse of the curve, or by segmental instability, with symptoms of continuous back and/or leg pain, mostly when in an upright position with axial loading of the spine, and asymptomatic when lying down and resting. If decompression is performed at the apex of the degenerative curve, progression of the curve is very likely. This means that decompression contributes to destabilization of a fragile balance. This procedure can be detrimental and completely disable a patient (Fig. 15).

The same may be true when an isolated decompression is done at the bottom of a rigid curve, i.e., at the transition to the mobile part of the lumbar spine, usually $\mathrm{L} 4 / 5$ or $\mathrm{L} 5 / \mathrm{S} 1$. The rigid curve above may decompensate these segments in translation, and the spine may fall off the balance. In most of these cases, therefore, a decompression should be accompanied by a fusion with or without stabilization in situ (Fig. 11).

In younger patients, in whom a partial correction is planned, a decompression may be achieved by the correction procedure alone, and a formal decompression may not be necessary (Figs. 4, 5, 6).

\section{Correction procedures}

If the balance in the frontal plane is achieved and there is a proper sagittal alignment, there is no need to look for a correction. Stabilization and fusion in situ may be more
Fig. 10 Pathophysiology of adult, degenerative scoliosis with its clinical presentation

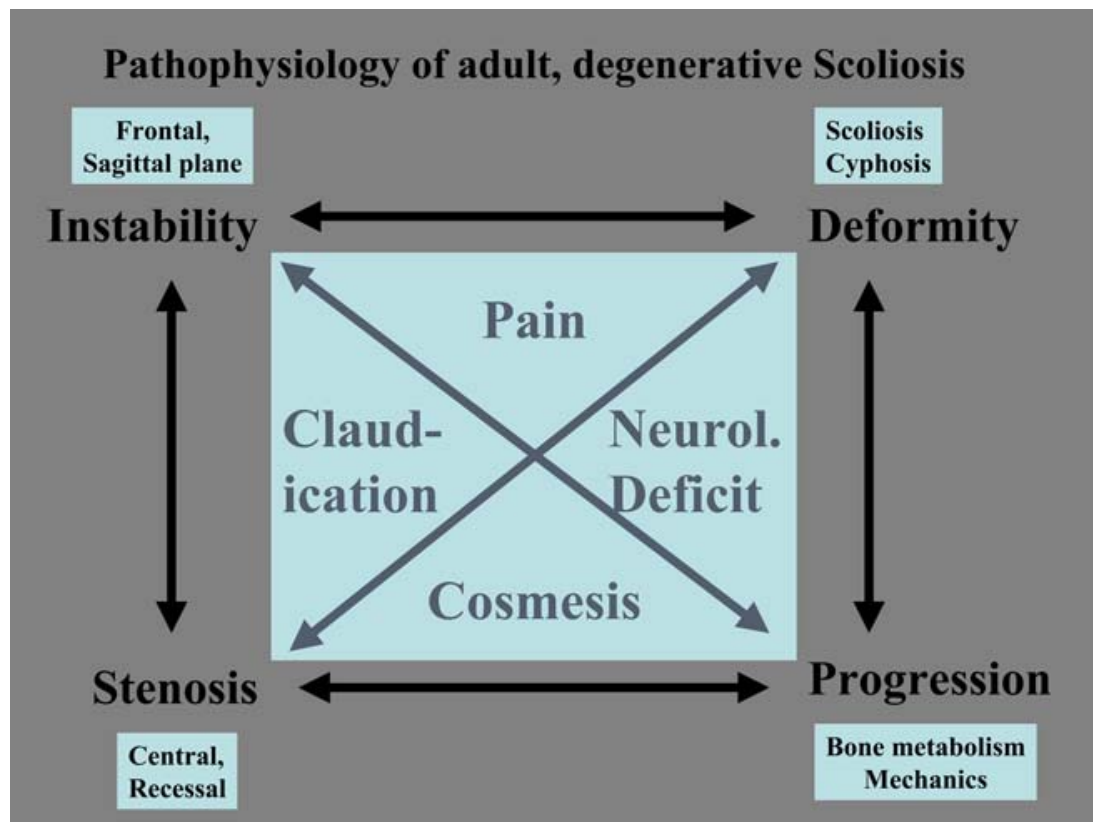



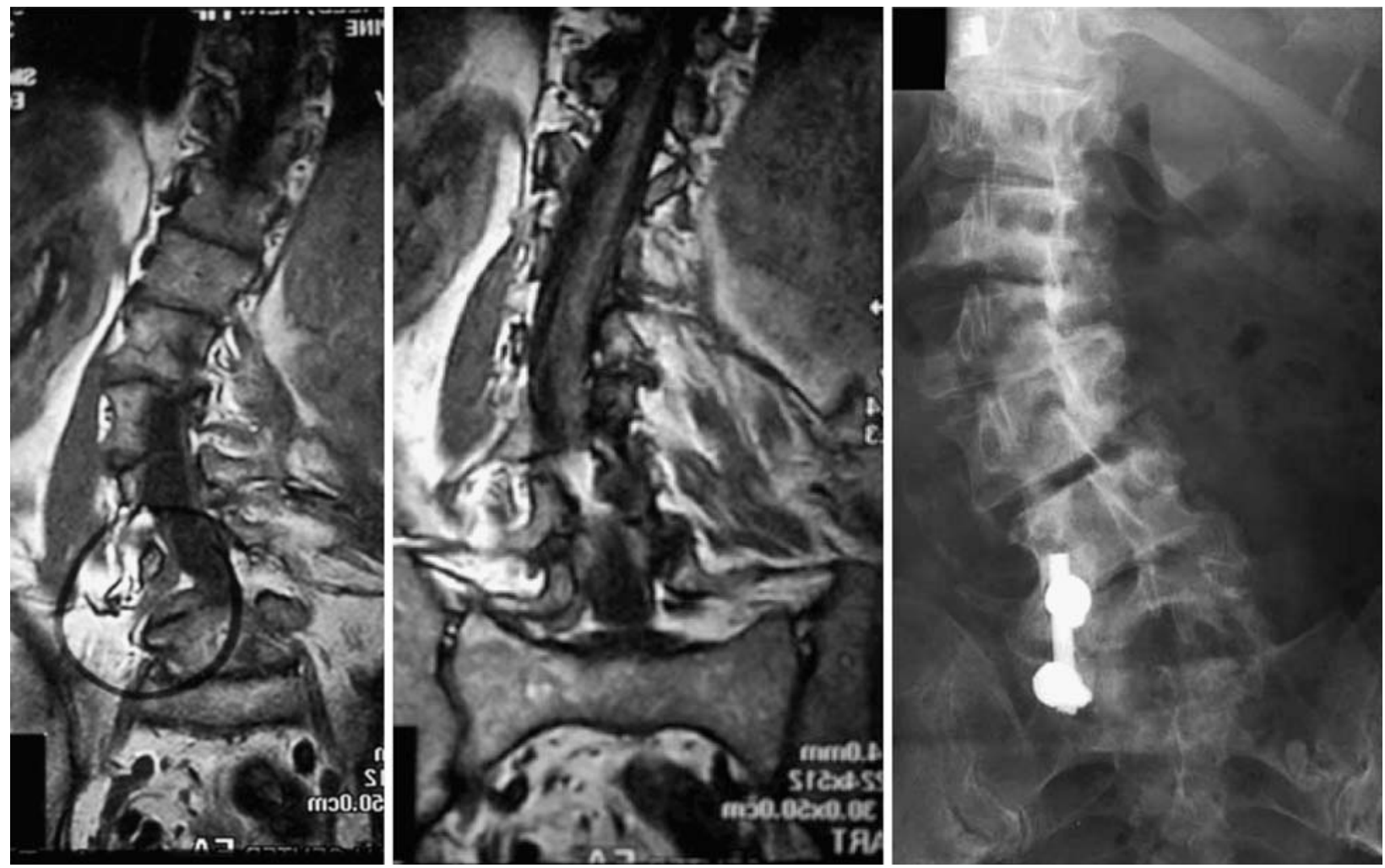

Fig. 11 A 79-year-old female patient, known to have scoliosis since late twenties. Persistent L5 radiculopathy after selective foraminal decompression 4 years ago. Now again decompression on the left with a local stabilization and fusion in order to prevent progression of the curve. Disappearance of the radiculopathy

than appropriate in which case overall decompensation of the spine can usually then be avoided. Often it is tempting to correct the lumbar curve and/or thoracolumbar deformity since this is almost always possible when a rigorous posterior release and pedicular fixation is done.

In cases where the lumbar and/or thoracolumbar curve is a degenerated countercurve to an idiopathic thoracic curve which is either completely rigid or has been fused in adolescence, a correction needs to be carefully thought about, since the thoracic curve cannot adapt to the corrected curve below, resulting in a decompensation of the thoracic spine, imbalance, and a chronic pain syndrome in the lower thoracic or thoracolumbar spine (Fig. 16).

In cases of apparent flat back syndrome (primary degenerative lumbar scoliosis are usually combined with a loss of lumbar lordosis), correction is mostly necessary if the chronic back pain should be addressed. This needs an extensive release of the posterior elements (facets, facet joint capsules, ligamentous components, and sometimes facet joint osteotomies), and mostly the anterior elements (disc calcified, posterior longitudinal ligament calcified). If necessary, the disc can be released through the same posterior approach at L2 and below. An anterior release is indeed rarely needed, unless there is a relevantly rigid scoliosis component present with translational dislocations, or significant anterior osteophytes bridging the segments solidly, where an anterior release may help to balance the frontal and sagittal plane (Fig. 17). Such a combined procedure, however, may not be well tolerated by more elderly patients over 60 years or in reduced general health. Selective segmental spinal osteotomies, mostly transpedicular reduction osteotomies, may be necessary to balance the spine.

In addition to the important release in the case of a planned correction, it may also be necessary to extend the fixation and fusion beyond the major curve into the thoracic countercurve, to guarantee appropriate sagittal as well as frontal overall balance of the spine. If that is not considered, the patient may end up with a collapse of the cranial segment adjacent to the fixation, or with a secondary instability both most probably due to an overloaded segment in an unbalanced correction. It is clear that such a magnitude of surgery is only possible in patients with a robust general condition, since the surgery may take several hours and the blood loss may be significant. For these reasons, we recommend that surgery is considered as early as possible, when unfavourable developments and progression can be foreseen. This is a particularly important consideration in female patients entering menopause who regularly have back and/ 

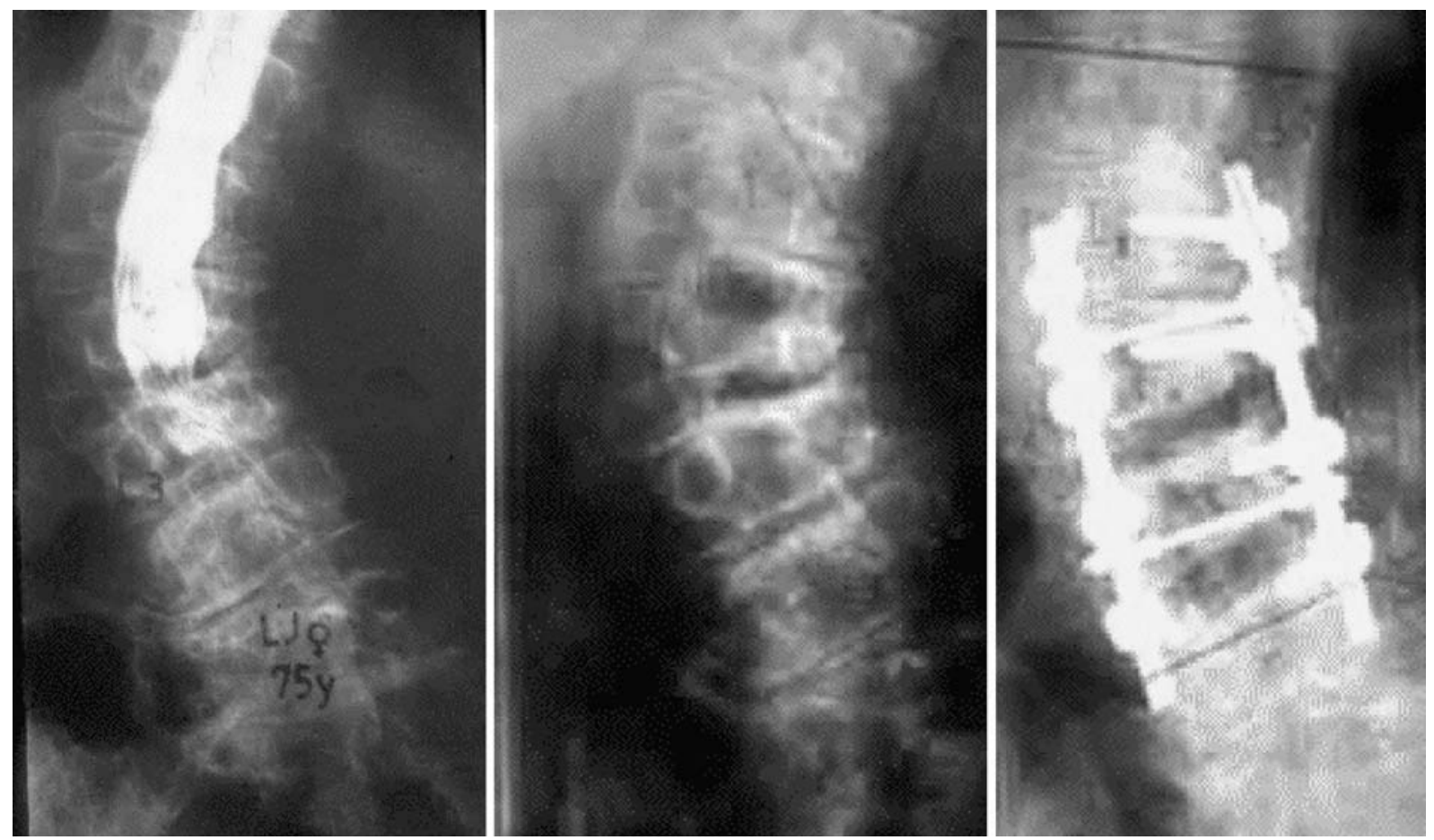

Fig. 12 A 75-year-old actress with subacute paraparesis, no relevant back pain: decompression, stabilization, and fusion in situ. Almost complete recovery

or leg pain with beginning osteoporosis and significant degeneration and tendency of flat back.

If an anterior release is necessary, the surgery can be staged or done in the same surgical session. Anterior instrumentation in patients who need a secondary posterior procedure is not necessary or even contraindicated, since the anterior instrumentation may limit posterior correction. The posterior pedicular systems nowadays allow a powerful manipulation, correction, and stabilization of the lumbar spine, as long as a proper posterior release precedes the corrective and stabilization procedure. The anteriorly released segments, however, may be prepared for anterior interbody fusion by removing the disc, freshening the endplates and filling the intervertebral space with cancellous bone or even a solid tricortical spacer.

The correction of a deformity is therefore achieved after an appropriate release either by stepwise correction through segmental instrumentation or by one or more segmental osteotomies for the frontal or sagittal realignment of the spine.

In case a lumbar curve is still flexible, which can be assessed by sidebending and flexion/extension views, and a certain compensation of the thoracic countercurve can be anticipated, a posterior correction, stabilization and fusion with or without decompression are sufficient. This is also done when a curve is clearly progressive.
Stabilization and fusion procedures

If back pain is a leading symptom, with or without leg pain, a fusion is usually indicated. The levels to be included in the fusion can be difficult to determine. Generally speaking, it is unfavourable to stop a fusion at L1 or even L2, i.e., below the thoracolumbar junction, because it may easily lead to decompensation above the fusion, with localized disc degeneration, segmental collapse, translational instability and secondary kyphosis [28].

The most critical segment to consider whether or not to include in a fusion is the lumbosacral junction. It takes all the movement off of the lumbar spine and is the most difficult fusion to be achieved. A high percentage may remain with a non-union due to the unfavourable mechanical conditions of this junction between the two major lever arms of the fused spine and the rigid pelvis $[8,12,17,26,30,37,57,68]$. The incidence of the nonunion varies quite remarkably in the literature (5-30\%) $[12,18]$. Various types of instrumentation have been designed to enhance the fusion healing to the sacrum [12, $30,37,60]$. They are mostly based on an increasingly more solid anchorage in the sacrum, or in the sacrum and iliac wings at the same time. None of these instrumentations have been clinically demonstrated to significantly overcome the problem of non-union in the complex pathology of degenerative scoliosis. The most certain approach to eliminate the problem of non-union is a $360^{\circ}$ circumferential fusion at the lumbosacral junction. In order to avoid the anterior approach, unless 

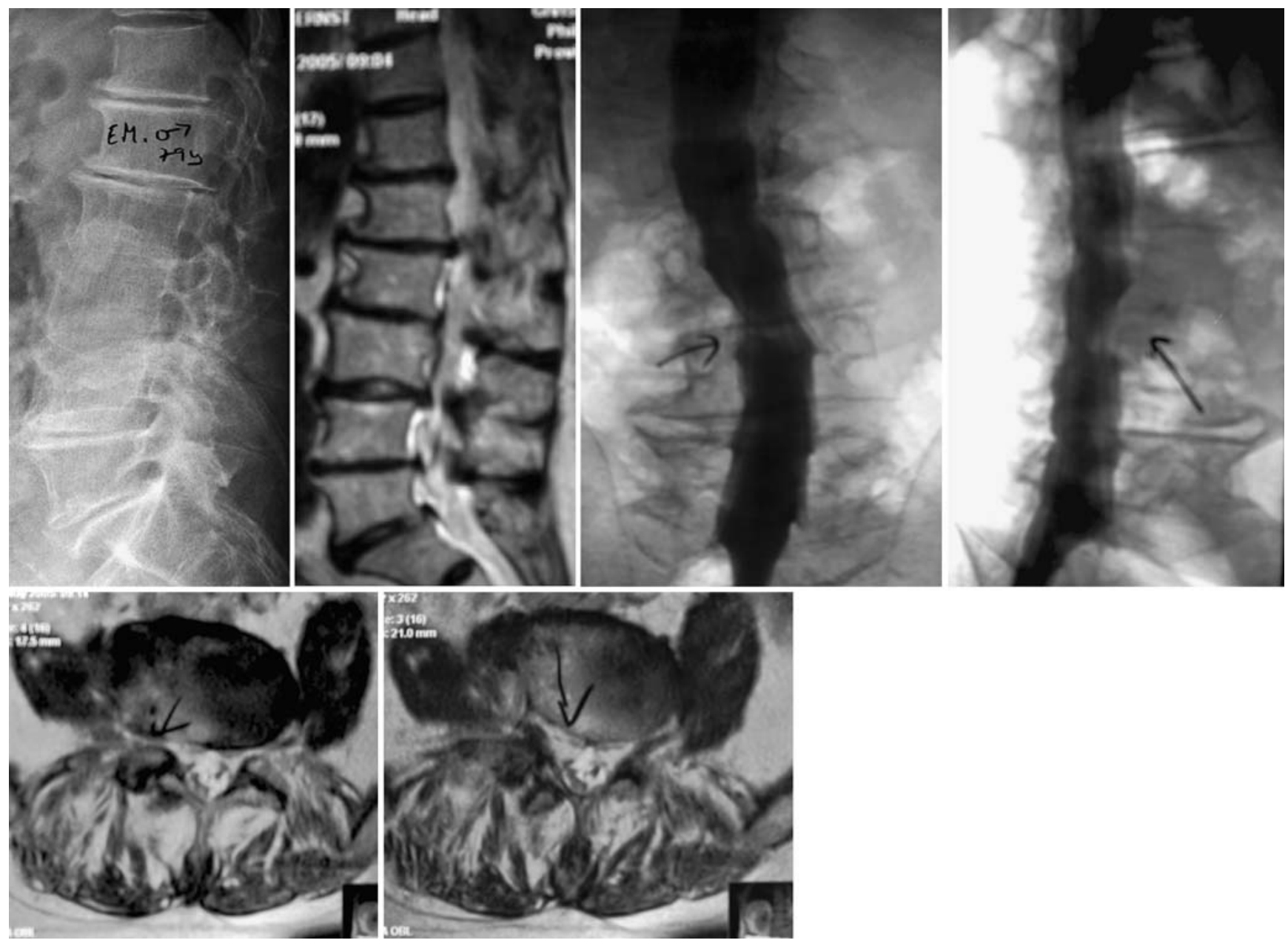

Fig. 13 A 79-year-old hard-working male farmer with relatively mild back pain, however, severe left leg pain, corresponding L3 (4) root, with proven root compression: Microsurgical decompression only, no attempt to touch the severely degenerated kyphoscoliotic spine

needed for an extensive release, the refinement and standardization of posterior lumbar interbody fusion (PLIF) technique using specifically designed cages has become a well-controlled procedure (Fig. 18). Controlled clinical studies need to show whether the clinical reality will support the theoretically valid concept of load sharing at the lumbosacral junction in order to avoid non-unions.

Obviously, it would be preferable to omit the lumbosacral junction during the surgery for lumbar scoliosis correction and stabilization. However, depending on the cause of the curve, the lumbosacral junction usually is degenerated: disc space narrowing, facet joint arthritis, vertebral obliquity and possibly rotational deformity and sometimes even spontaneous fusion of L5 to S1 might be a consequence of a lumbosacral transitional anomaly or a progressed degeneration. In such cases, if there is no certainty about the rigidity of $\mathrm{L} 5 / \mathrm{S} 1$ it is better to include it in the fusion/stabilization since a stop of the fusion at L5 puts a lot of stress on the lumbosacral junction and is able to "loosen" it up with a secondary pain syndrome. A fusion to L5 even in case of a "healthy" L5/S1 segment may overload that and induce a secondary degeneration with loss of disc height, facet joint incongruency and arthritis and possibly disc herniation (Fig. 19) [31, 37, 56, 63].

A fusion to the sacrum may not only have an impact on the iliosacral joints but also on the hip joints specifically when there is already osteoarthritis of the hip. The disease process may be accelerated by the change of the load to the hip joint.

For posterior surgery, pedicular and/or translaminar screw fixation may be considered [2, 4, 7, 40, 41]. In case correction is not the goal of the surgery, but towards stabilization and immobilization, respectively, of the arthritic, often hypertrophic facet joints, then the translaminar screw fixation may be a simple, little traumatic and minimally invasive procedure to achieve such a goal (Fig. 20). For a long fixation and correction, a pedicular system is the indication of choice. 
Fig. 14 Treatment options

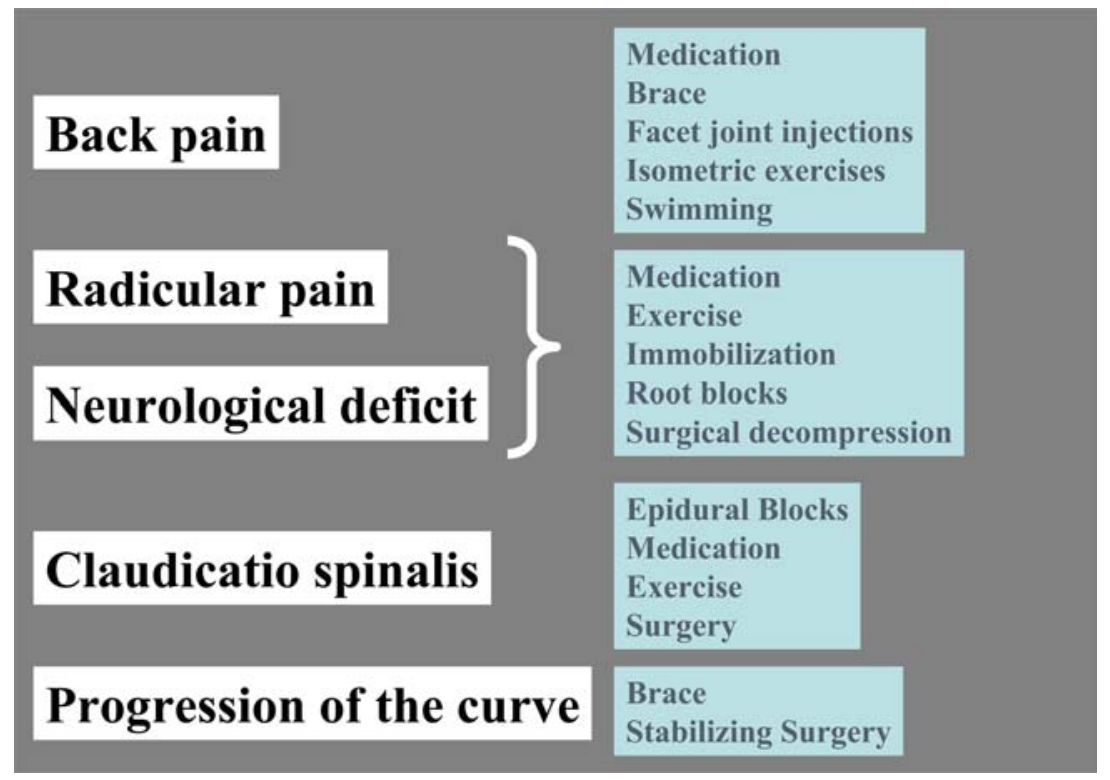

\section{Problems encountered in case of surgical treatment}

Length of fusion

It is increasingly understood today that the fusion should be avoided whenever possible. Unfortunately, up to now, we do not have better established treatment modalities available in severely degenerated and deformed spines. Therefore in severe adult degenerative scoliosis cases, the fusion is an integral part of a treatment plan. It is anticipated that within the lumbar spine, every segment should be spared if possible, in order not just to maintain some lumbar movement but also to spare further segments from degenerating. Discography and facet joint infiltrations as well as temporary immobilization in a body cast may help to determine the extent of the fusion. The radiologically moderately degenerated motion segment is not enough to be included in the fusion, as long as this segment does not really contribute to the pain suffered by the patient. It is, however, necessary to inform the patient that this concept of restricting the extent of the fusion may necessitate further surgery in case a spared segment may degenerate further and become symptomatic. The most problem segments to be included in a fusion are those below a curve in the lower lumbar spine.

Whether the emerging dynamic fixation devices or even disc arthroplasty will be an option in the surgical treatment of adult degenerated scoliosis remains to be considered as more experience is acquired with that kind of implant.

Inclusion of the lumbosacral segment

Patients with a lumbar or thoracolumbar curve have at least some degree of degeneration at L4/5 and/or L5/S1 segments. Although these segments may not be painful
Table 2 Symptoms and clinical signs to be addressed by surgical measures
1. Back pain:

\section{Radicular pain:}

3. Claudication symptoms:

4. Neurologic deficit:

5. Clearly progressive curve identified as discogenic, facet or instability pain, or pain due to an unbalancedspine in the sagittal (flat back or hypolordosis) and frontal planes identified by a clear pathomorphological equivalent, providing a compression or tension of one or more roots due to either a central stenosis of one or several levels, or due to a more lateral, recessal stenosis presenting as an individual root claudication ranging from sensory deficits, reflex absence or anomaly, radicular motor deficit, or paraparesis with bladder and sphincter problems 


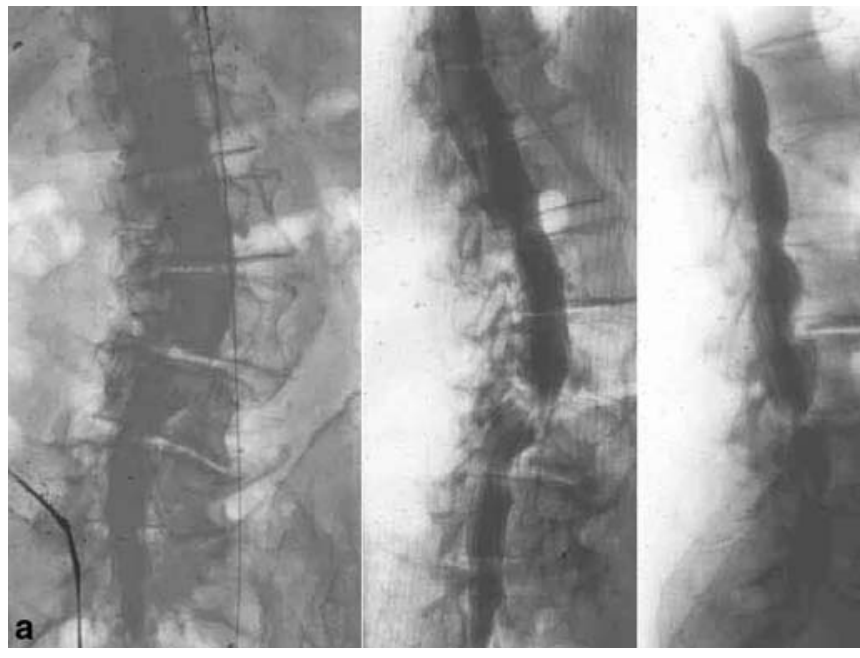

Fig. 15 A 76-year-old female patient with back pain and claudication symptoms in both legs. a When patient presented herself to a neurosurgical service, a decompression of the stenosis close to the apex of the curve was done. b 8 months later, progression of the curve, significant claudication symptoms, severe back pain and patient practically bedridden

at the time of the decision-making, they may soon become painful after a long-distance fusion has been performed above them. A rapid deterioration is then possible, which may necessitate a further extension of the fusion down to the sacrum. The expert's opinion is divided, whether in such cases a lumbosacral fusion should be included right from the beginning, or whether a wait and see attitude should be taken and only fuse the lumbosacral junction in case there are significant clinical problems from this area $[8,10,12,15,30,37]$.

Spinal segments adjacent to the fusion/level of fixation

A long fusion, which is often necessary in scoliosis, acts as a lever arm against the adjacent segments above and below. If the spine above (in adult lumbar scoliosis mostly the thoracic spine or the thoracolumbar junction) is rigid, either physiologically developed over the years, or acquired by a previous fusion of a thoracic curve, it may not follow the correction executed in the lumbar spine. This may result in a decompensation above the lumbar curve with an unbalanced overall spine, which may be the cause of further clinical problems. It is therefore crucial to understand through preoperative planning on whole spine X-rays as to how far a correction can be carried out without creating a secondary problem in the spine above (see also Fig. 16).

Many mid-lumbar and thoracolumbar curves have a short and sharp countercurve at the lumbosacral junction either including S1 and L5 only or also L4 with an oblique take off. This short curve is usually seen in the

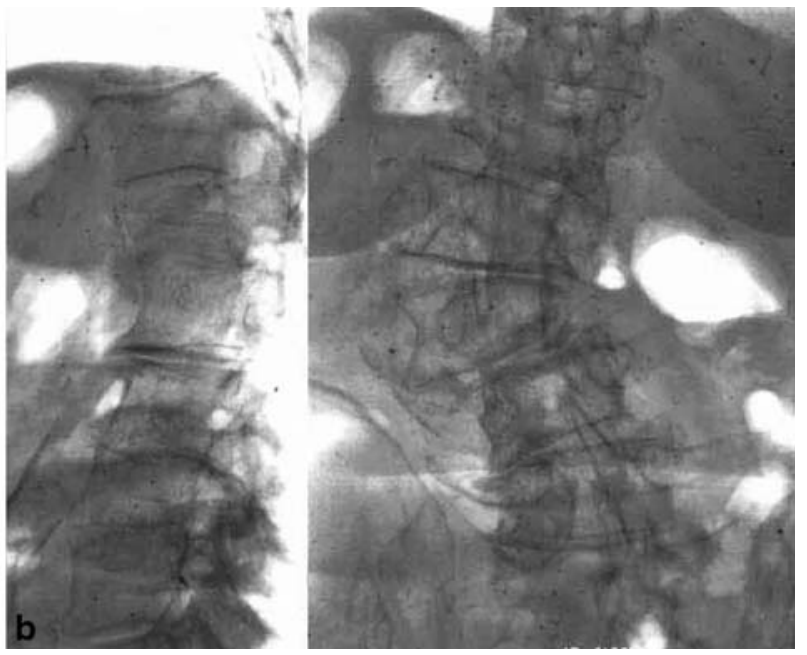

pelvis and leads to an overload of L3/4 or L4/5 [37]. These curves usually do not compensate a corrected curve above and have a bad prognosis [34, 37]. They may even progress and contribute significantly to the clinical syndrome of the patient. In most cases, it is therefore recommended to consider inclusion of this lumbosacral junction into the fusion.

\section{Previous scoliosis surgery}

More than 25 years after Harrington instrumentation became increasingly popular for idiopathic scoliosis surgery, we see a growing number of patients who had such a surgery in their adolescence. These patients, who are now between their late twenties and early forties, are sometimes presenting themselves with severe secondary problems below their thoracolumbar fusion and fixation. This problem is particularly severe in patients who were left with a flat lumbar spine because of the distractive-kyphotic effect of the Harrington instrumentation in the sagittal plain (Fig. 5). They may have degenerated adjacent segments below, along with spinal stenosis, and chronic low back pain due to the overstressed paraspinal muscles [23, 69]. These problems are not unique to patients who had Harrington instrumentation. They can also be found in patients who had non-instrumented fusions with long-term body cast immobilization, or who had not been treated at all for a relevant thoracolumbar idiopathic scoliosis.

In the majority of cases, a simple correction, decompression, and instrumented fusion does not remedy the problem. These patients need a complete overall rebalancing of the spine by one or multiple osteotomies. This problem is so complex and multifactorial that it needs consideration in a separate review and can only be alluded to in this article. 


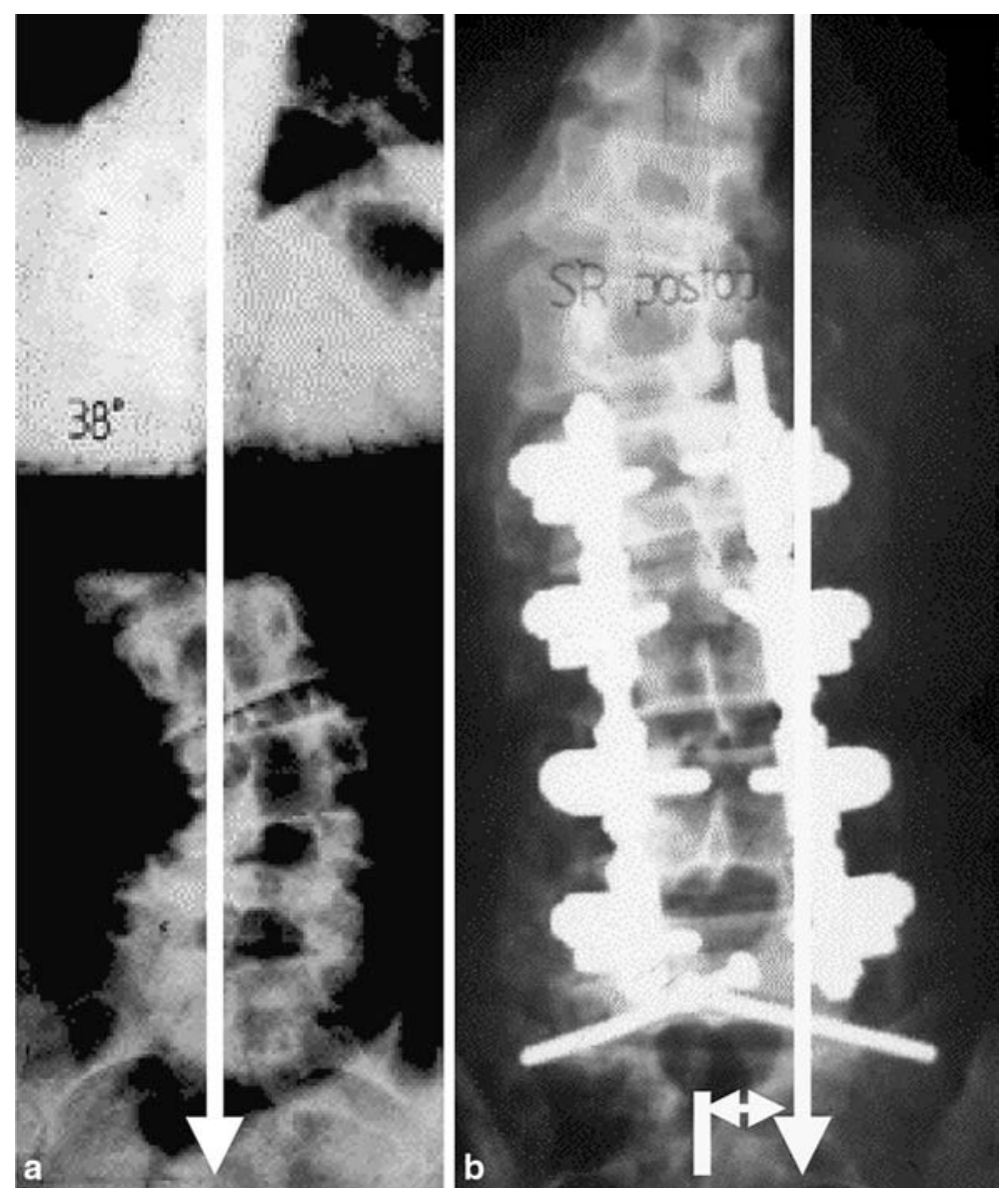

Fig. 16 A 54-year-old female patient who has been fused in late adolescence for a idiopathic right convex thoracic curve (uninstrumented fusion); a secondary lumbar curve with degenerative changes, b instrumented correction and fusion with decompensation of balance because of the rigidity of the thoracic curve due to the fusion and secondary back pain in the mid- and lower thoracic spinal area

Age and general medical condition of the patient

The age of the patient-most of the patients with scoliosis and significant, symptomatic degenerative alterations of the curve or counter curve, are older than 50 years and often have systemic diseases such as cardiac or vascular disease or diabetes, and are very demanding for the responsible anaesthesiologist who must also consider the possible aggravating significant blood loss and surgical time in this procedure. The periand post-operative management of such a patient may need an interdisciplinary approach among the surgeon, the anaesthesiologist, and an internist who accompany this patient, until his/her general condition post-operatively has stabilized and returned to the pre-operative situation. Also, the elderly and frail patients need a longer and more intensive rehabilitation time in order to recover optimally [49].

\section{Osteoporosis}

Osteoporosis is a major concern in the treatment of adult scoliosis. The majority of elderly patients with degenerative scoliosis are female, and osteoporosis may become an issue at the time of the menopause. This is the time when degenerative scoliosis may become increasingly symptomatic because the curve may progress due to the asymptomatic load on weakened vertebrae, which get more wedged and deformed. With the progression of the curve, the patient may get more symptomatic in terms of back pain as well as of the claudication pain.

The surgical treatment is complicated by the weak bone where implants are more difficult to be anchored and fixed, making the instrumented fusion prone to instrumentation-related complications. The industry has offered all kinds of instrumentations with big diameter screws and adapted threads to improve bone purchase. Cement reinforcement of the screw anchorage is another alternative which has been advocated $[8$, 37]. In our experience, instrumentation success is not really so dependent on the size of the screw. The whole construct must respect a principle of balance as 


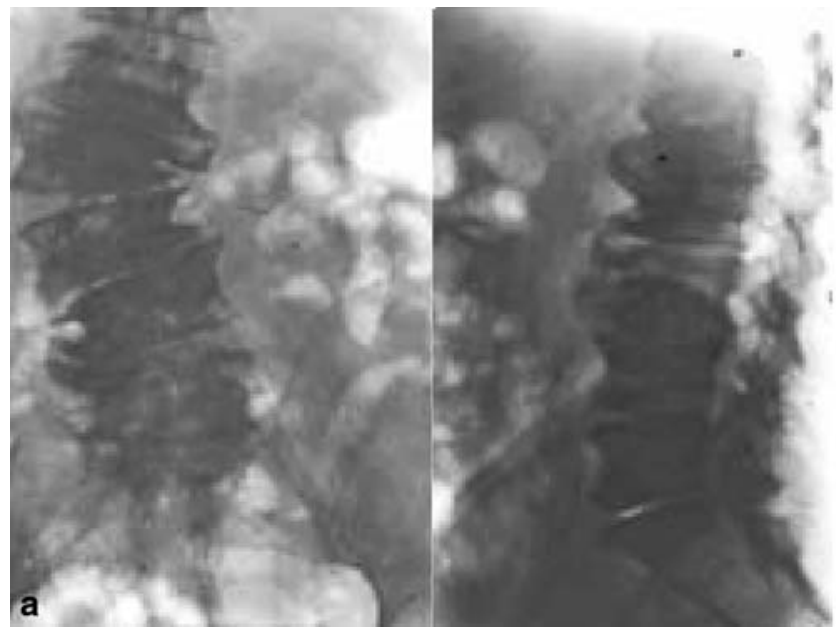

Fig. 17 a A 71-year-old male physician with severe degenerative scoliosis and with spinal stenosis and flat back. b Decompression and posterior stabilization, however, correction of the lumbar kyphosis absent, because no anterior release was done and the posterior release was also insufficient. Postoperatively no claudication symptoms anymore, however, persistent back pain

demonstrated in the Asian world where bamboo is used in the construction of gigantic buildings. Each anchorage is loaded one against the other in an overall

Fig. 18 Type 2 scoliosis (progressive idiopathic scoliosis in adult life): A 39-year-old female patient with AIS, significant loss of lumbar lordosis preoperatively. Postoperative restoration of lordosis and circumferential fusion with PLIF at the lumbosacral junction in order to avoid non-union
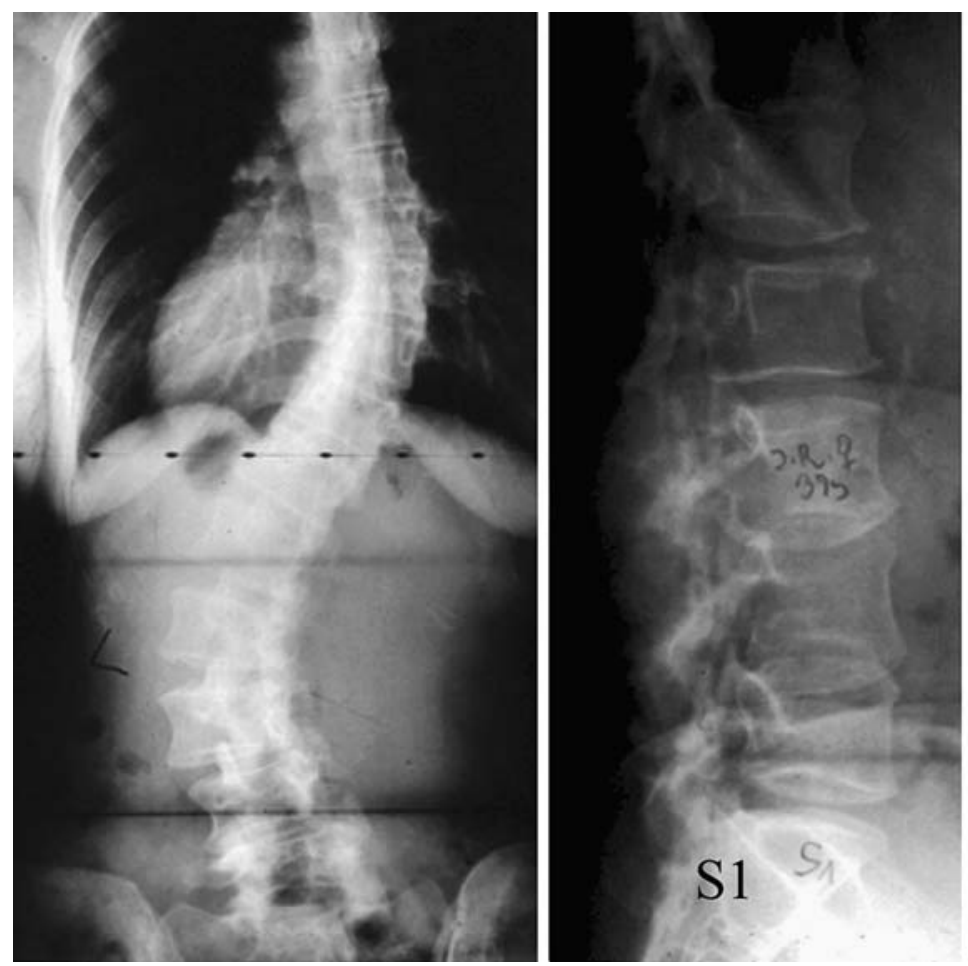

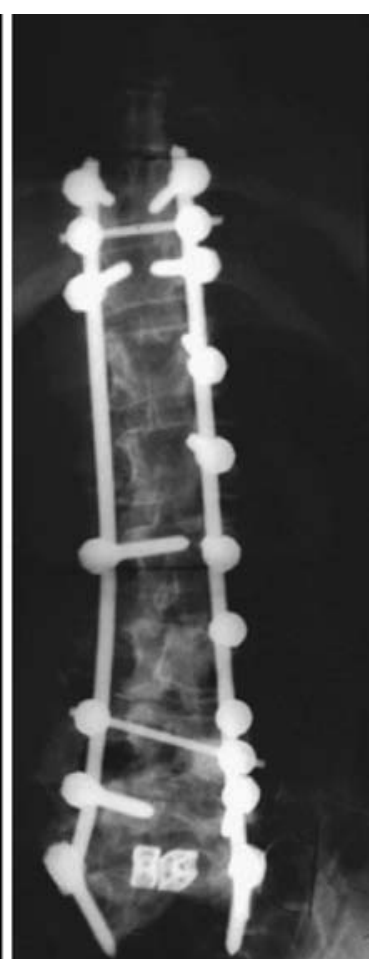



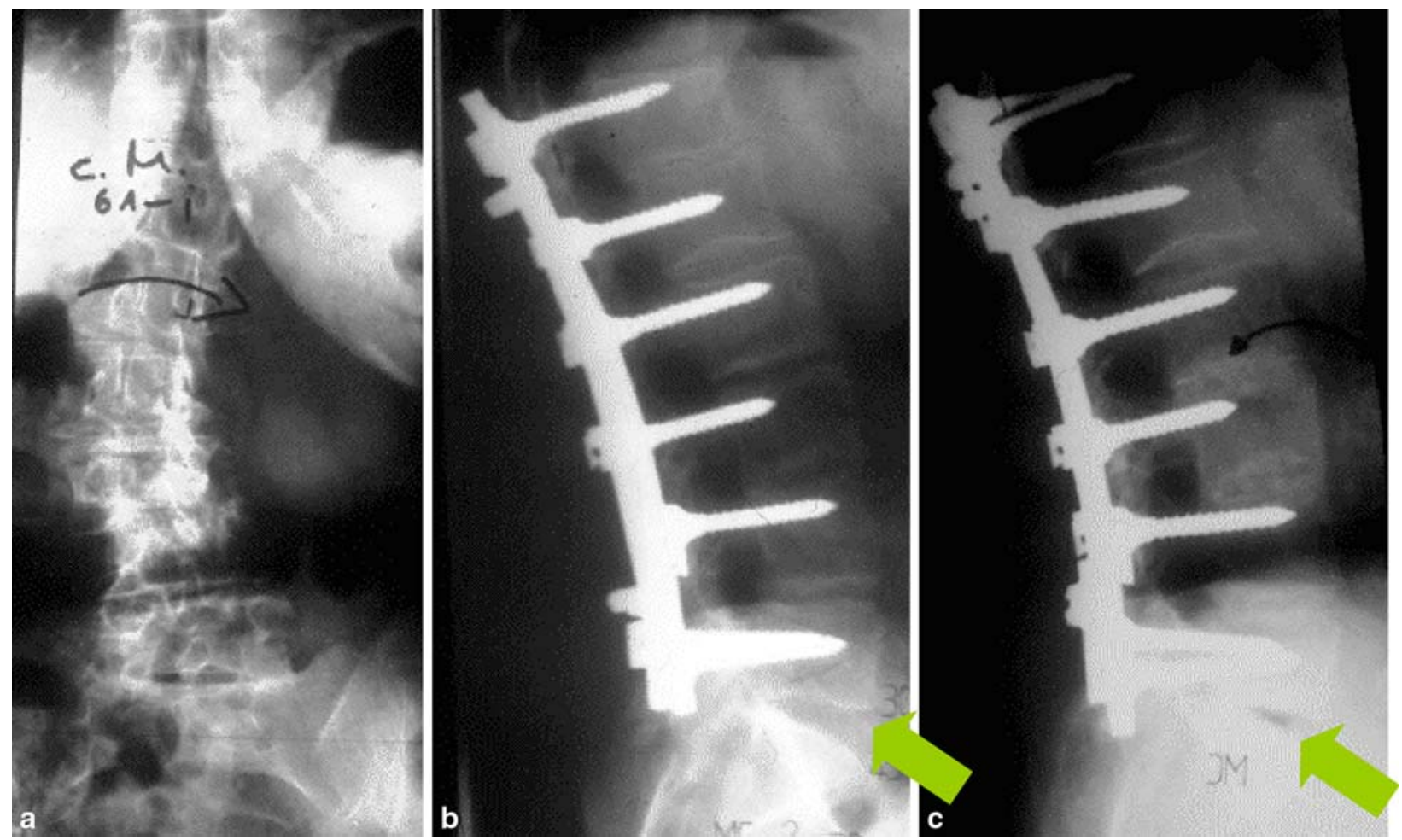

Fig. 19 a A 61-year-old female patient with back pain and claudication symptoms. b Decompression, stabilization and fusion, while omitting L5/S1; 1 year postoperatively disc space L5/S1 still quite high, c 28 months postoperatively, collapsed disc space L5/S1 with $\mathrm{L} 5$ radicular syndrome due to foraminal stenosis

We have performed more than 250 surgeries in adult scoliosis, and the complication rate has improved since we did a retrospective study almost 10 years ago on our first 75 adult scoliosis cases. In the first series, the complication rate was comparable to those in other studies and the overall results were satisfactory $[56,59$, $61,63]$. With the present expertise in this field and the referral of increasingly complex cases, the complications have shifted. The most prominent problems we encounter in this surgery are problems of proper balance and non-union at the lumbosacral junction, as well as limitations of the surgical options in medically frail patients, resulting in only partial improvement. The nonunion problem has lost its significance in the last 3 years since we systematically do circumferential fusions at the lumbosacral junction, using either PLIF or ALIF cages in combination with posterior pedicular instrumentation.

There is a quite substantial risk for mild or severe post-operative nerve root paresis [47]; some of them recover spontaneously.

The outcome needs to be age matched since the demands of daily life, professional performance, and leisure activities vary substantially in the different age groups. Most of the patients who are still professionally active do not return to their previous work if it was a physically demanding job, but almost all of those had already stopped working before the surgery, because of pain limitations. When analyzed, regarding their overall daily activity by different questionnaires [50], most of these patients irrespective of age have improved in almost all categories of quality of life, and the use of regular pain medication is reduced substantially in more than $70 \%$ of these patients. The assumption that this surgery may be too much for elderly patients could not be substantiated, at least not in our institution, where we have done a comparative study of general complications in an age and comorbidity matched cohort of patients undergoing hip arthroplasty surgery - an accepted surgery in elderly patients - and patients undergoing a major spine surgery like degenerative lumbar scoliosis surgery [49]. The major problem of these patients after surgery, once surgical complications and implant failures have not occurred, is the residual back pain mostly as an expression of muscular spasms and pain due to unbalanced or chronic contractures of the paravertebral muscles.

\section{Conclusion}

The complexity of the relationship between clinical signs, symptoms, pathomorphology, and pathophysiology of adult - mostly lumbar, degenerative scolio- 

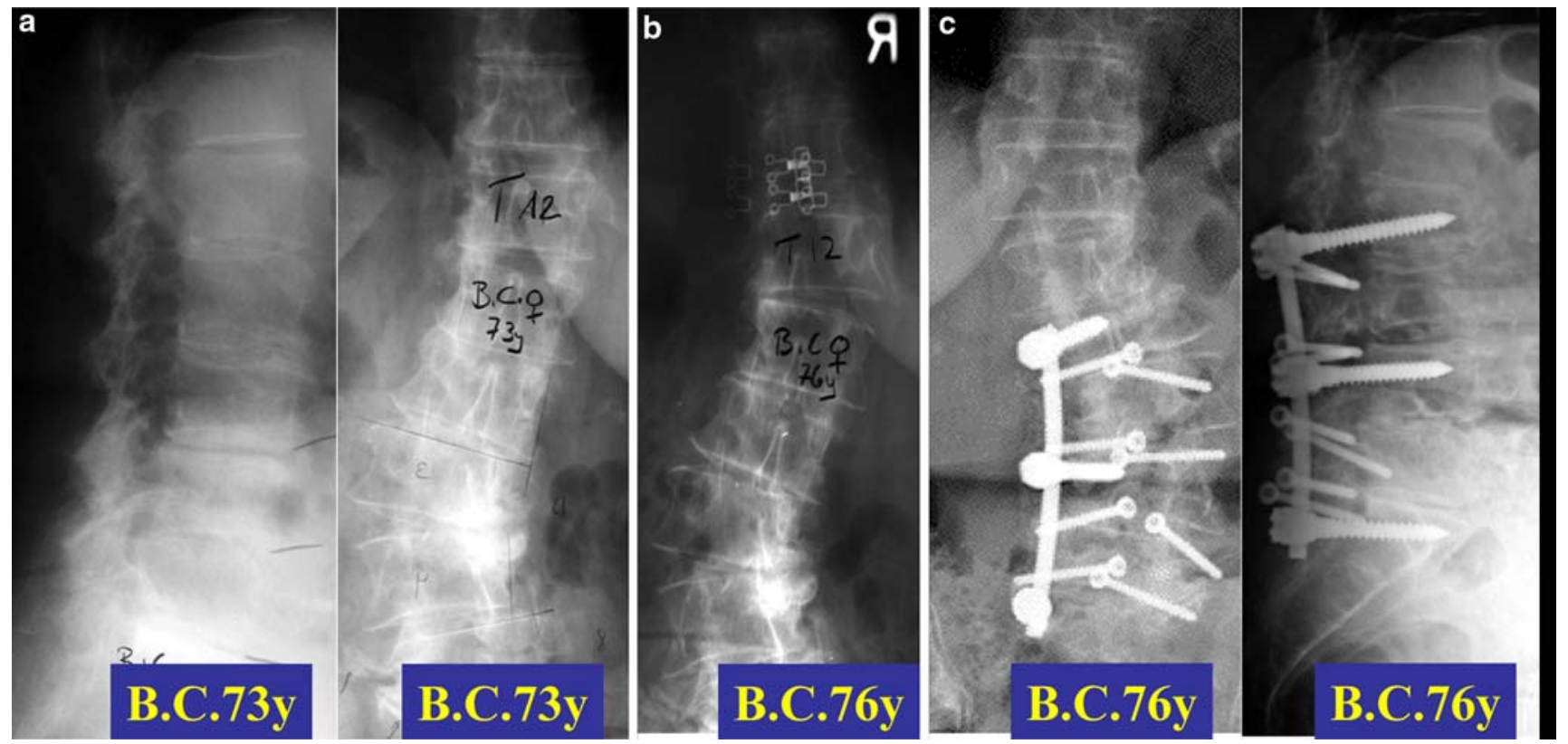

Fig. 20 a A 73-year-old female patient with progressive degenerative scoliosis with a foot drop and claudication symptoms as well as moderate back pain with which the patient can live (a and b). c 10 months postoperatively. After a minimal surgery for decompression and stabilization in situ, partial recovery of the foot drop. Back pain irrelevant, although the flat back is unchanged

sis - remains one of the big challenges in spinal surgery. The combination of the relatively uniform major signs and symptoms, namely instability, stenosis, unbalanced deformity, and possible curve progression on one side, and the complex pain pattern, the claudication, and possible neurological signs and symptoms on the other side allow a variety of clinical patterns, which need to be analysed both, systematically and individually in order to find concrete solutions for each of them, and to tailor a surgical procedure which best serves the rational expectations of the patient and surgeon.

\section{References}

1. Aebi M (1987) Adult scoliosis. Therapeutische Umschau 44:757-763

2. Aebi M (1988) Correction of degenerative scoliosis of the lumbar spine. A preliminary report. Clin Orthop Relat Res: $80-86$

3. Albert TJ, Purtill J, Mesa J, McIntosh T, Balderston RA (1995) Study design: health outcome assessment before and after adult deformity surgery. A prospective study discussion p. 2005. Spine 20:2002-2004

4. Ali RM, Boachie-Adjei O, Rawlins BA (2003) Functional and radiographic outcomes after surgery for adult scoliosis using third-generation instrumentation techniques. Spine 28(11):11631169
5. Ascani E, Bartolozzi P, Logroscino CA, Marchetti PG, Ponte A, Savini R, Travaglini F, Binazzi R, Di Silvestre M (1986) Natural history of untreated idiopathic scoliosis after skeletal maturity. Spine 11(8):784-789

6. Benner B, Ehni G (1979) Degenerative lumbar scoliosis. Spine 4:548

7. Berven S (2003) Point of view. Spine 28(11):1169-1170

8. Boachie-Adjei O, Gupta MC (1999) Adult scoliosis + deformity. AAOS Instructional Course Lectures 48(39):377-391

9. Bradford DS (1988) Adult scoliosis. Current concepts of treatment. Clin Orthop Relat Res: 70-87

10. Bradford DS, Tay BK, Hu SS (1999) Adult scoliosis: surgical indications, operative management, complications and outcome. Spine 24:2617-2629
11. Briard JL, Jegou D, Cauchoix J (1979) Adult lumbar scoliosis. Spine 4:526-532

12. Bridwell KH (1996) Where to stop the fusion distally in adult scoliosis: L4, L5, or the sacrum? Instr Course Lect 45:101-107

13. Byrd JA, Scoles PV, Winter RB et al (1986) Adult idiopathic scoliosis treated by anterior and posterior spinal fusion. Orthop Trans 10:31-32

14. Deviren V, Berven S, Kleinstueck F, Antinnes J, Smith JA, Hu SS (2002) Predictors of flexibility and pain patterns in thoracolumbar and lumbar idiopathic scoliosis. Spine 27(21):23462349 
15. Deyo RA, Cherkin DC, Loeser JD, Bigos SJ, Ciol MA (1992) Morbidity and mortality in association with operations on the lumbar spine. The influence of age, diagnosis, and procedure. $\mathrm{J}$ Bone Joint Surg Am 74(4):536-543

16. Dick J, Boachie-Adjei O, Wilson M (1992) One-stage versus two-stage anterior and posterior spinal reconstruction in adults. Comparison of outcomes including nutritional status, complications rates, hospital costs, and other factors. Spine 17(8 Suppl):S310 S316

17. Dickson JH, Mirkovic S, Noble PC, Nalty T, Erwin WD (1995) Results of operative treatment of idiopathic scoliosis in adults. J Bone Joint Surg Am 77(4):513-523

18. Edwards CC, Bridwell KH, Patel A, Rinella AS, Jung Kim Y, Berra A, Della Rocca GJ, Lenke LG (2003) Thoracolumbar deformity arthrodesis to L5 in adults: the fate of the L5-S1 disc. Spine 28(18):2122-2131

19. Epstein JA, Epstein BS, Jones MD (1979) Symptomatic lumbar scoliosis and degenerative changes in the elderly. Spine 4:542-547

20. Fowles JV, Drummond DS, L'Ecuyer S, Roy L, Kassab MT (1978) Untreated scoliosis in the adult. Clin Orthop Relat Res Jul-Aug(134):212-217

21. Frazier DD, Lipson SJ, Fossel AH, Katz JN (1997) Study design: associations between spinal deformity and outcomes after decompression for spinal stenosis. Spine 22:2025-2029

22. Glassman SD, Bridwell K, Dimar JR, Horton W, Berven S, Schwab F (2005) The impact of positive sagittal balance in adult spinal deformity. Spine 30(18):2024-2029

23. Grobler LJ, Moe JH, Winter RB et al. (1978) Loss of lumbar lordosis following surgical correction of thoracolumbar deformities. Orthop Trans 2(2):39

24. Grubb SA, Lipscomb HJ (1992) Diagnostic findings in painful adult scoliosis. Spine 17(5):518-527

25. Grubb SA, Lipscomb HJ, Coonrad RW (1988) Degenerative adult onset scoliosis. Spine 13:241-245

26. Grubb SA, Lipscomb HJ, Suh PB (1994) Results of surgical treatment of painful adult scoliosis. Spine 19:16191627

27. Guillaumat M (1993) Les scolioses lombaires de l'adulte. In: SOFCOT, Chirurgie du Rachis de l'Adulte. Paris: Expansion Scientifique Française: 199222

28. Hanley Jr EN (1996) Indications for fusion in the lumbar spine. Bull Hosp Joint Dis 55:154-157

29. Healy J, Lane J (1985) Structural scoliosis in osteoporotic women. Clin Orthop 195:216
30. Horton WC, Holt RT, Muldowny DS (1996) Controversy. Fusion of L5-S1 in adult scoliosis. Spine 21:2520-2522

31. Jackson RP, Simmons EH, Stripinus D (1983) Incidence of severity of back pain in adult idiopathic scoliosis. Spine 8(7):749-756

32. Johnson JR, Holt RT (1988) Combined use of anterior and posterior surgery for adult scoliosis. Orthop Clin North Am 19:361-370

33. Korovessis P, Piperos G, Sidiropoulos P, Dimas A (1994) Adult idiopathic lumbar scoliosis. A formula for prediction of progression and review of the literature. Spine 19(17):19261932

34. Kostuik JP (1979) Decision making in adult scoliosis. Spine 4(6):521-525

35. Kostuik JP (1980) Recent advances in the treatment of painful adult scoliosis Clin Orthop 147:238-252

36. Kostuik JP, Bentivoglio J (1981) The incidence of low back pain in adult scoliosis. Spine 6(3):268-273

37. Kostuik JP, Hall BB (1983) Spinal fusions to the sacrum in adults with scoliosis. Spine 8(5):489-500

38. Kostuik JP, Israel J, Hall J (1973) Scoliosis surgery in adults. Clin Orthop 93:44

39. Linville DA, Bridwell KH, Lenke LG, Vedantam R, Leicht P (1999) Complications in the adult spinal deformity patient having combined surgery. Does revision increase the risk? Spine 24(4):355-363

40. Marchesi DG, Aebi M (1992) Pedicle fixation devices in the treatment of adult lumbar scoliosis. Spine 17:S304-S309

41. Marchesi DG, Thalgott JS, Aebi M (1991) Application and results of the AO internal fixation system in nontraumatic indications. Spine 16:S162S169

42. McKinley LM, Gaines RW, Leatherman KD (1977) Adult scoliosis: recognition and treatment. J Ky Med Assoc 75:235-238

43. Micheli L, Riseborough E, Hall J (1977) Scoliosis in the adult. Orthop Rev 6:27

44. Nachemson A (1979) Adult scoliosis and back pain. Spine 4:512

45. Nuber GW, Schafer MF (1986) Surgical management of adult scoliosis. Clin Orthop Relat Res: 228-237

46. Ogilvie JW (1992) Adult scoliosis: evaluation and nonsurgical treatment. Instr Course Lect 41:251-255

47. Pateder DB, Kostuik JP (2005) Lumbar nerve root palsy after adult spinal deformity surgery. Spine 30(14):16321636

48. Ponseti IV (1968) The pathogenesis of adult scoliosis. In: Zorab PA (eds) Proceedings of second symposium on scoliosis causation. E \& Livingstone, Edinburgh
49. Reindl R, Steffen T, Cohen L, Aebi M (2003) Elective lumbar spinal decompression in the elderly: is it a high-risk operation? Can J Surg 46(1):43-46

50. Rinella A, Bridwell K, Kim Y, Rudzki J, Edwards C, Roh M, Lenke L, Berra A (2004) Late complications of adult idiopathic scoliosis primary fusions to L4 and above: the effect of age and distal fusion level. Spine 29(3):318-325

51. Robin G, Span Y, Steinberg R et al (1982) Scoliosis in the elderly: a followup study. Spine 7:355

52. Sapkas G, Efstathiou P, Badekas AT, Antoniadis A, Kyratzoulis J, Meleteas E (1996) Radiological parameters associated with the evolution of degenerative scoliosis. Bull Hosp Joint Dis 55:40-45

53. Scheier HJ (1991) Degenerative scoliosis. Aktuelle Probleme in Chirurgie und Orthopädie 41:73-74

54. Schwab F, Dubey A, Pagala M, Gamez L, Farcy JP (2003) Adult scoliosis: a health assessment analysis by SF-36. Spine 28(6):602-606

55. Schwab F, el-Fegoun AB, Gamez L, Goodman H, Farcy JP (2005) A lumbar classification of scoliosis in the adult patient: preliminary approach. Spine 30 (14):1670-1673

56. Shapiro GS, Taira G, Boachie-Adjei (2003) Results of surgical treatment of adult idiopathic scoliosis with low back pain and spinal stenosis: a study of long-term clinical radiographic outcomes. Spine 28(4):358-363

57. Simmons EH, Jackson RP (1979) The management of nerve root entrapment syndromes associated with the collapsing scoliosis of idiopathic lumbar and thoracolumbar curves. Spine 4:533-541

58. Simmons EH, Tramwell TR (1983) Operative management of adult scoliosis. Surg Musculoskeletal Syst 4:427496

59. Simmons Jr ED, Kowalski JM, Simmons EH (1993) The results of surgical treatment for adult scoliosis. Spine 18:718-724

60. Smith JA, Deviren V, Berven S, Bradford DS (2002) Does instrumented anterior scoliosis surgery lead to kyphosis, pseudarthrosis, or inadequate correction in adults? Spine 27(5):529534

61. Sponseller PD, Cohen MS, Nachemson AL, Hall JE, Wohl ME (1987) Results of surgical treatment of adults with idiopathic scoliosis. J Bone Joint Surg Am 69(5):667-675

62. Stagnara P (1969) Scoliosis in adults. Surgical treatment of severe forms. Excerpta Med Found Int Cong 192 
63. Stagnara P, Fleury D, Fauchet R et al (1975) Scolioses majeures de l'adultes supérieures à 100-183 cas traités chirurgicalement. Rev Chir Orthop 61:101122

64. Swank S, Lonstein JE, Moe JH, Winter RB, Bradford DS (1981) Surgical treatment of adult scoliosis. A review of two hundred and twenty-two cases. $\mathbf{J}$ Bone Joint Surg 63-A:268-287

65. Takahashi S, Delécrin J, Passuti N (2002) Surgical treatment of idiopathic scoliosis in adults: an age-related analysis of outcome. Spine 27(16):17421748
66. Tribus CB (2003) Degenerative lumbar scoliosis: evaluation and management. $\mathbf{J}$ Am Acad Orthop Surg 11(3):174-183

67. van Dam BE (1988) Nonoperative treatment of adult scoliosis. Orthop Clin North Am 19:347-351

68. van Dam BE (1988) Operative treatment of adult scoliosis with posterior fusion and instrumentation. Orthop Clin North Am 19:353-359

69. van Dam BE, Bradford DS, Lonstein JE, Moe JH, Ogilvie W, Winter RB (1987) Adult idiopathic scoliosis treated by posterior spinal fusion and Harrington instrumentation. Spine 12:3236
70. Velis KP, Healey JH, Schneider R (1988) Osteoporosis in unstable adult scoliosis. Clin Orthop Relat Res: 132141

71. Winter RB, Lonstein JE (1983) Adult scoliosis. AAOS Instruc Course Lect 32:170-191

72. Winter R, Lonstein J (1983) Adult scoliosis. In: Evarts CMC (ed) Instructional course lectures. American Academy of Orthopaedic Surgeons, vol XXXII. CV Mosby, St. Louis

73. Winter RB, Lonstein JE, Denis F (1988) Pain patterns in adult scoliosis. Orthop Clin North Am 19:339-345 